\title{
On the Diversity of Long-Term Temperature Responses to Varying Levels of Solar Activity at Ten European Observatories
}

\author{
Vladimir Kossobokovi,2, Jean-Louis Le Mouël2, Vincent Courtillot ${ }^{2}$ \\ ${ }^{1}$ Institute of Earthquake Prediction Theory and Mathematical Geophysics, Russian Academy of Sciences, Moscow, Russia \\ ${ }^{2}$ Geomagnetism and Paleomagnetism, Institut de Physique du Globe de Paris, Sorbonne Paris Cité, Paris, France \\ Email:volodya@mitp.ru, lemouel@ipgp.fr, courtil@ipgp.fr
}

How to cite this paper: Kossobokov, V., Le Mouël, J.-L. and Courtillot, V. (2019) On the Diversity of Long-Term Temperature Responses to Varying Levels of Solar Activity at Ten European Observatories. Atmospheric and Climate Sciences, 9, 498-526. https://doi.org/10.4236/acs.2019.93033

Received: April 3, 2019

Accepted: July 22, 2019

Published: July 25, 2019

Copyright $\odot 2019$ by author(s) and Scientific Research Publishing Inc. This work is licensed under the Creative Commons Attribution International License (CC BY 4.0).

http://creativecommons.org/licenses/by/4.0/

cc) (i) Open Access

\begin{abstract}
We analyze ten of the longest (127 to 230 year-long) time series of European daily temperatures available from five different Köppen-Geiger climate classes. We split these according to the level of solar cycle activity ( $\mathrm{H}$ for "higher than median" and L for "lower than median"). This reveals coherent patterns in the temperature differences: when $T_{H}-T_{L}$ are stacked according to their calendar date, the daily averages from January 1 to December 31st disclose characteristic features in addition to the dominant annual seasonal wave, namely variations up to $2^{\circ} \mathrm{C}$ lasting for about 1.5 to 3 months. The five observatories at intermediate latitudes in a band from Oxford in the West to Prague in the East (same climate class) have very similar signatures. These similarities are most unlikely to be due to pure chance (confirmed by confidence levels in excess of $99 \%$ with the Kolmogorov-Smirnov and Kuiper nonparametric tests). The $\mathrm{T}_{H}-\mathrm{T}_{\mathrm{L}}$ patterns carry a regional signature, modulated by a more local response function. On the other hand, northern European observatories (St Petersburg and Arkhangelsk), those south of the Alps (Milan and Bologna), and the easternmost one in Astrakhan, corresponding to different climate classes, have different signatures. Similarly, preliminary study of long air pressure recordings confirms what emerges from the analysis of temperatures. These new observations lead us to conclude that the climate in different regions presents different responses to variations in solar activity. Moreover, the distributions of the lower, middle, and higher quartiles of the temperature and pressure indices in solar cycles with high versus low activity are significantly different, providing further robust statistical confirmation to this conclusion (confidence level higher to much higher than $99 \%$ using the Kuiper test).
\end{abstract}




\section{Keywords}

Solar Variability, Multi-Decadal Temperature Changes, Long Temperature Series, Nonparametric Hypotheses Testing, Kolmogorov-Smirnov Test, Kuiper Test

\section{Introduction}

In the present paper, we propose a short but in-depth overview of a very specific topic, i.e., the statistical testing of hypotheses related to solar influence on regional temperature regimes at the time scale of several decades. In two previous papers, we analyzed the longest available temperature series from Prague, Bologna and Uccle [1] [2]. In the former paper, we partitioned daily minimum temperatures (TN), maximum temperatures (TX), and daily ranges $(\Delta \mathrm{T}=\mathrm{TX}-$ TN) in two subsets as a function of high vs low solar activity, using the method of superimposed epochs. We found that differences between curves for high vs low solar activity in the three stations displayed similar patterns with significant amplitudes $\left(\sim 1^{\circ} \mathrm{C}\right)$ and time constants $\sim 3$ months. In the latter paper, we used the two-sample Kolmogorov-Smirnov statistics, multiple shuffles of data and other partitions to demonstrate that the separation between the probability distribution functions of temperature extrema and ranges in the high vs low classes was statistically significant and robust. We suggested that solar activity could account, at least in part, for the multi-decadal variations in temperature observed at these European sites in the past two centuries.

Part of this work was criticized in a paper by Legras et al. [3]. We responded and concluded that our original conclusions stood [4] [5]. Our discussion was supported by Wolff et al. [6] who encouraged interested scientists to read not only the final papers published in Climate of the Past [3] [7], but also the associated comments and responses available in Climate of the Past Discussions [4].

The importance of our original conclusions warrants further analysis; in this paper, we extend our original study by including more observatories with long series of data, as well as by applying an additional method of statistical testing. We have therefore further analyzed, in the same way as in the two original papers, daily minimum, maximum and range of temperatures at additional observatories selected from the 24 European stations with the daily air minimum and maximum temperature observations over more than a hundred years [8]. We selected (Figure 1) three additional observations with very long series within the same Köppen-Geiger climate zone as Prague, Bologna and Uccle, namely, Oxford (from 1853/01/01 to 2001/12/31, 149 years in total), Frankfurt (1870/01/01 to $2011 / 03 / 31,141.25$ years), and Wien (1855/02/01 to 2004/12/31, 149.83 years), and four at observatories in other Köppen-Geiger climate classes throughout Europe, including Milan (1870/01/01 to 2008/11/30, 139.92 years), Archangelsk (1881/01/01 to 2009/09/29, 127.75 years), St Petersburg (1881/01/01 to 2011/09/30, 

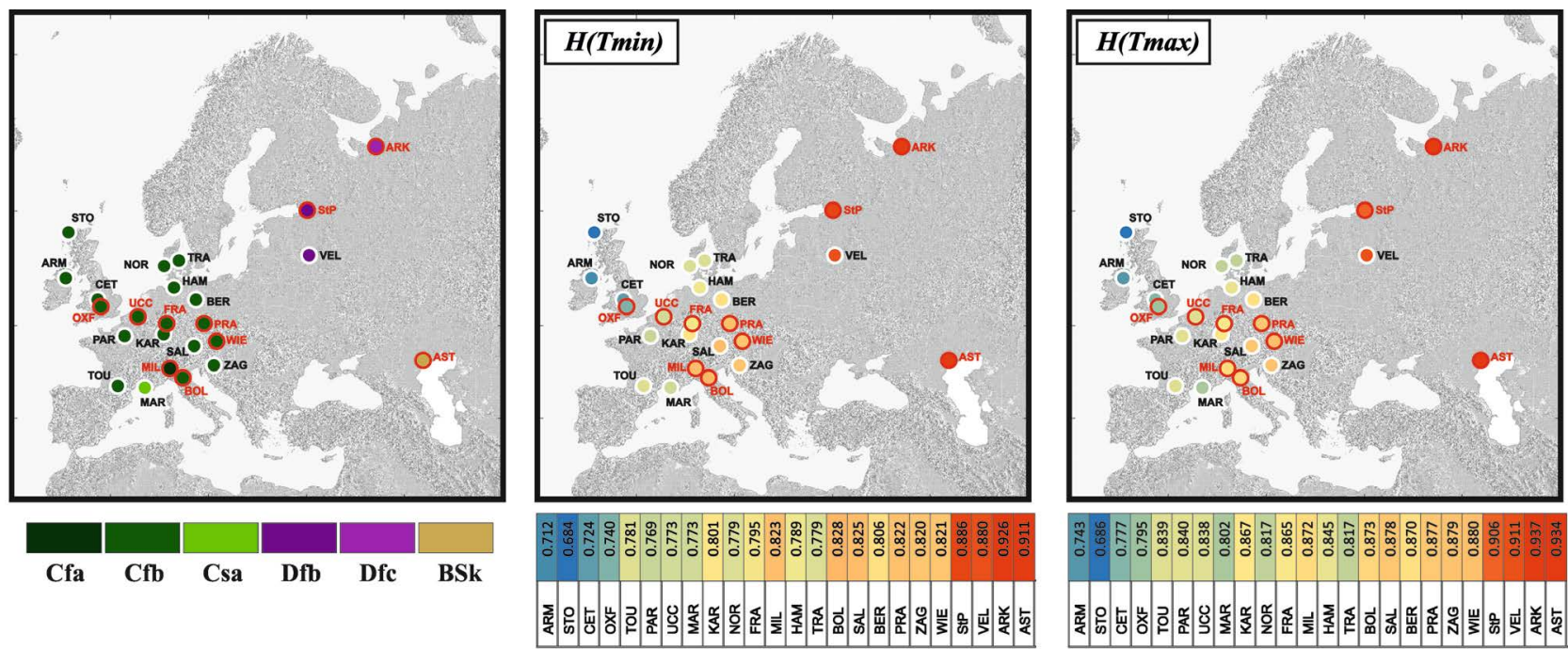

Figure 1. Geographical location of the 24 European stations with the daily air minimum and maximum temperature observations over more than a hundred years. Each location is color-coded in respect to the Köppen-Geiger climate classes [9] on the left, normalized Shannon's entropy $\mathrm{H}^{*}$ for Tmin in the middle, and Tmax on the right [8]. The selected locations of the10 stations listed in Table 1 are highlighted with red outline.

131.75 ears), and Astrakhan (1881/01/01 to 2011/09/30, 131.75 years). These series are naturally shorter than the original three (Table 1), yet they are long enough for reliable application of statistics.

Testing hypotheses requires a high standard of statistical analysis as was often recalled by Andrey Nikolaevich Kolmogorov (1903-1987). The essence of a valid statistical data analysis is summarized in the introduction to Chapter 14 "Statistical Description of Data" by Press et al. ([10], page 609) and we follow this in our research.

\section{Data}

As announced in the introduction, we complement our earlier studies with an additional seven of the longest series from the European Climate Assessment and Dataset, ECA \& D [11] available at

https://eca.knmi.nl/dailydata/predefinedseries.php (last accessed 10 July 2019). These come in addition to the three series used in our previous papers. Specifically, we have used non-blended temperature data with long durations (from 127 years up to 230 years), with less than $2 \%$ of missing data at eight out of ten observatories (the missing data is $6.3 \%$ of TN, $11.5 \%$ of TX, and $11.6 \%$ of $\Delta \mathrm{T}$ at Astrakhan and $5.3 \%$ of $\mathrm{TN}, 20.4 \%$ of TX, and $22.9 \%$ of $\Delta \mathrm{T}$ at Arkhangelsk). Blended data, such as the famous Central England temperature series of [12], include some amount of processing that can lead to spurious effects in the statistics which are to be avoided [10]. Note that due to the definition used by the ECA \& D editors, even the best data with the highest quality code in their database are designated as "suspect". Some authors recommend performing a data treatment known as "homogenization", in the hope of removing or smoothing out potential artefacts. For instance, table 1 in [3] 
Table 1. The ten European stations ordered by the TN entropy [8]. Notes: (a) The Köppen-Geiger climate classes [9]: Cfa-warm temperate climate, fully humid, with hot summer; $\mathrm{Cfb}$-warm temperate climate, fully humid, with warm summer; Csa-warm temperate climate with dry and hot summer; Dfb—snow climate, fully humid, with warm summer; Dfc_-snow climate, fully humid, with cool summer and cold winter; BSk—cold steppe climate; (b) The datasets for Milan and Bologna are reduced to the period starting from 1870.

\begin{tabular}{cccccccc}
\hline Station & Abr & Class & Lat & Lon & Data span & H(TN) & H(TX) \\
\hline Oxford (UK) & OXF & Cfb & 51.767 & -1.267 & $1853-2001$ & 3.041 & 3.269 \\
\hline Uccle (Belgium) & UCC & Cfb & 50.800 & 4.350 & $1833-2001$ & 3.179 & 3.444 \\
\hline Frankfurt (Germany) & FRA & Cfb & 50.117 & 8.667 & $1870-2011$ & 3.270 & 3.557 \\
\hline Wien (Austria) & WIE & Cfb & 48.233 & 16.350 & $1855-2004$ & 3.373 & 3.618 \\
\hline Prague (Czech Republic) & PRA & Cfb & 50.091 & 14.419 & $1775-2005$ & 3.379 & 3.607 \\
\hline Milan (Italy) & MIL & Cfa & 45.472 & 9.189 & $1870-2008$ & 3.385 & 3.584 \\
\hline Bologna (Italy) & BOL & Cfb & 44.483 & 11.250 & $1870-2008$ & 3.404 & 3.590 \\
\hline St Petersburg (Russian Federation) & StP & Dfb & 59.967 & 30.300 & $1881-2011$ & 3.643 & 3.725 \\
\hline Astrakhan (Russian Federation) & AST & BSk & 46.283 & 48.050 & $1881-2012$ & 3.744 & 3.841 \\
\hline Arkhangelsk (Russian Federation) & ARK & Dfc & 64.500 & 40.733 & $1881-2009$ & 3.808 & 3.851 \\
\hline
\end{tabular}

provides a special "excerpt" on homogeneity. These authors check results for the 1901-2007 period (i.e., the ECA \& D file TEMP_19012009_homogeneity.txt) and point out five "suspect" stations. But, according to the file which they used, only 7 out of 126 stations in Europe are found to be "usefup", whereas 118 are "suspect" and 1 "doubtfup" [8]. It is difficult to understand how many of the results based on these European observations could have been obtained with "suspect" data. Homogeneity checking that rejects $95 \%$ of all European data and stations does not appear to be very useful or reasonable. That is why ECA \& D managers note that the "homogeneity analysis is subject to further research, as there is no well-established testing procedure for daily data"

(https://www.ecad.eu//FAQ/index.php accessed on 27 June 2018). In our studies, TN and TX values are all of the highest quality code in the ECA \& D at each location (i.e., "Flag $=0$ ", which means "valid").

As in our previous papers, we use the sunspot (Wolf) number as a proxy in order to analyze whether we can detect any significant contributions to temperatures that could be linked to variations in solar activity. The longest series of values is available at the world data center for the sunspot index at the Royal observatory in Brussels ([13] available at http://www.sidc.be/silso/datafiles, last accessed 10 July 2019). We use the annual average of the sunspot series from 1775 (that is the onset of the temperature series in Prague, the longest available) to 2005. We split the solar cycles themselves into cycles of low and high activity (Figure 2). The generally accepted dates of onsets (and terminations) of solar 

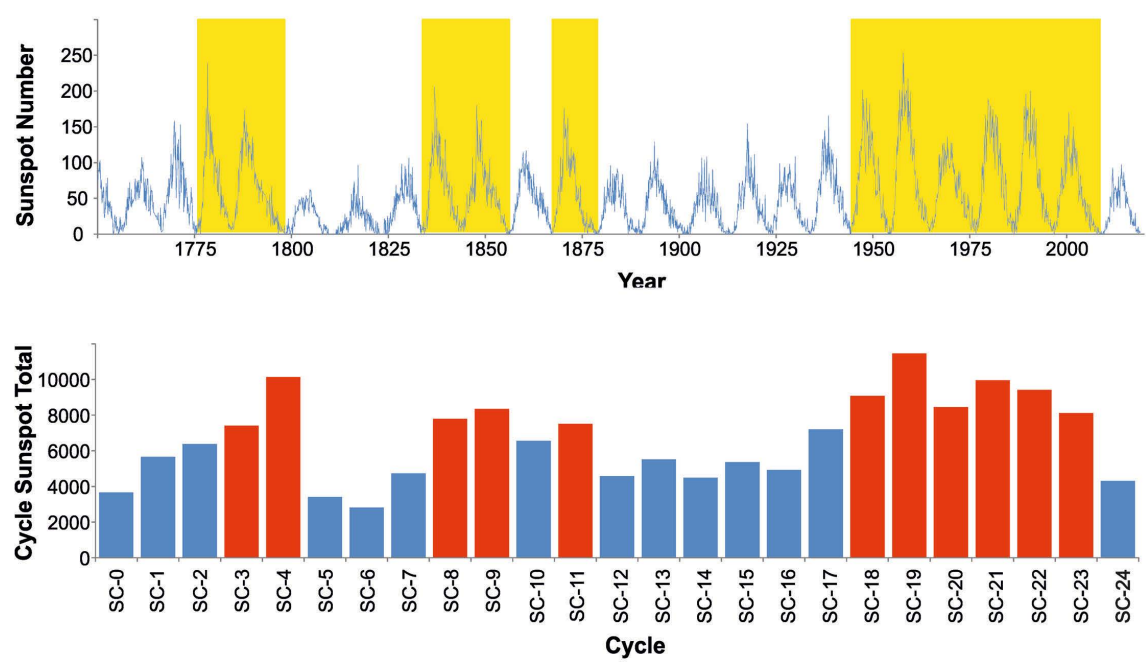

Figure 2. The monthly mean sunspot numbers (SIDC-team, 2019) on top of their solar cycle totals.

cycles 3 to 23 are from http://www.sidc.be/silso/versionarchive (see also table 1 in [1]). We use the number of sunspots for each year month $n(i)$, then sum up the total number of sunspots in each one of the 21 cycles under consideration $\left(N_{j}=\Sigma n\left(i_{j}\right)\right.$ for all years months $i_{j}$ belonging to cycle $\left.j\right)$. The median $\mathrm{M}$ of the 21 $N_{j}$ values is equal to 7400 . High-activity cycles are defined as those for which $N_{j}>M$, and low-activity cycles those for which $N_{j}<M$. High-activity cycles are numbers 3 and 4, 8 and 9,11, and from 18 to 23; low activity cycles are numbers from 5 to 7,10 , and from 12 to 17 (Figure 3). We separate the daily temperature values $\mathrm{T}(\mathrm{t})$ into two classes, $\mathrm{H}$ and $\mathrm{L}$, in the following way: the temperature $\mathrm{T}(\mathrm{t})$ of any day $\mathrm{t}$ belonging to a High-activity cycle is assigned to ensemble $\mathrm{H}$ and, respectively, the temperature $\mathrm{T}(\mathrm{t})$ of any day $\mathrm{t}$ belonging to a Low-activity cycle is assigned to ensemble $\mathrm{L}$. The times of high-activity cycles are marked with yellow background in Figure 2 and Figure 3. We use the method of superimposed epochs to stack the data from each class according to their calendar date, and divide by the number of years to yield $\langle\mathrm{T}\rangle(\mathrm{t}), \mathrm{t}=1, \ldots, 366$. We finally apply a 21-day centered moving average to the epoch mean curves: a 3-week period is both long enough to stabilize the noisy daily values and yet short enough that features with monthly and longer time constants are well preserved. In the following, we compare those mean data in subsets $\mathrm{H}$ vs $\mathrm{L}$, and also in other subsets defined in a similar way.

Finally, for the purpose of a pilot analysis of climate characteristics other than temperatures, we considered three ECA \& D non-blended data of the daily Sea level pressure (PP;

https://www.ecad.eu//utils/downloadfile.php?file=download/ECA_nonblend_pp .zip; last visited 18 June 2018), namely, the longest available series from De Bilt (Netherlands, 1849/01/01 to 2018/05/31, 169.42 years) and the other two of stations Armagh (United Kingdom, 1850/01/01 to 2001/09/30, 151.75 years) and Paris-Montsouris (France, 1890/01/01 to 2017/12/31, 118 years). 

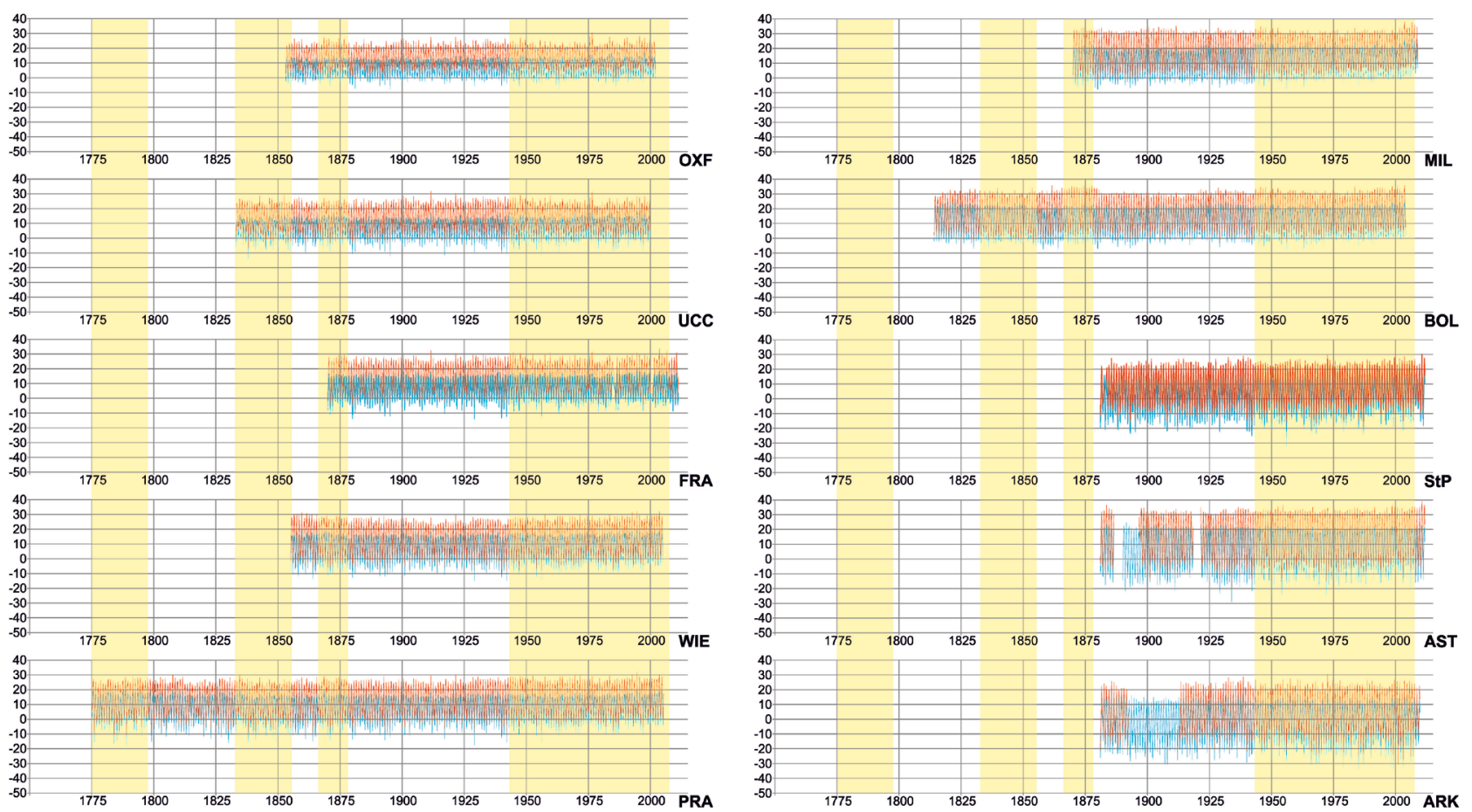

Figure 3. The 21-day moving averages of the ECA \& D non-blended daily TN (blue) and TX (red) at ten European stations.

\section{Results}

Seasonal variations of the 21-day averages of $\mathrm{TN}, \mathrm{TX}$ and $\Delta \mathrm{T}$ from January 1 to December 31 for four out of seven new observatories analyzed in this paper are shown in Figure 4. The TN, TX and $\Delta \mathrm{T}$ curves for the $\mathrm{H}$ class are in blue, red and green, while the curves for the L class are given in lighter colors, respectively. The annual temperature cycle is of course the dominant feature of all these figures, with annual amplitude variations ranging from $11^{\circ} \mathrm{C}$ (Oxford, Cfb class) to $30^{\circ} \mathrm{C}$ (Astrakhan, BSk class and Arkhangelsk, Dfc class) for TN, $15^{\circ} \mathrm{C}(\mathrm{Ox}-$ ford) to $34^{\circ} \mathrm{C}$ (Astrakhan) for $\mathrm{TX}$ and $4^{\circ} \mathrm{C}$ to $6^{\circ} \mathrm{C}$ for $\Delta \mathrm{T}$. Figure 5 shows the differences between temperature curves corresponding to high (TH) and low (TL) solar activity shown in Figure 4 (red curves for TX, blue TN and green $\Delta \mathrm{T}$ ). The sets of thin curves (symmetrical with respect to the abscissa axis) represent uncertainties of the differences, on each day, between the high activity and the low activity curves (in terms of the statistical error $\sigma$ ). We see that all curves are outside the range of error all or most of the time; hence, the differences between high and low activity periods are significant for all three temperature curves. And their values are not small: the differential effect between periods of high and low solar activity observed at the ten stations ranges from above $0.6^{\circ} \mathrm{C}$ and up to $2.5^{\circ} \mathrm{C}$ for any of the three temperature curves (see also figure 1 of [1] [2]). This is a significant effect, which is on the order of or larger than multi-decadal changes in global temperature in the past century.

In comments of the method, Legras et al. [3] reduced the number of pairs of temperature values required for the standard error estimate to $21 \times \mathrm{N}^{2}$ instead of $(21 \times N)^{2}$. In doing so, these authors overestimated the uncertainty by a factor of 


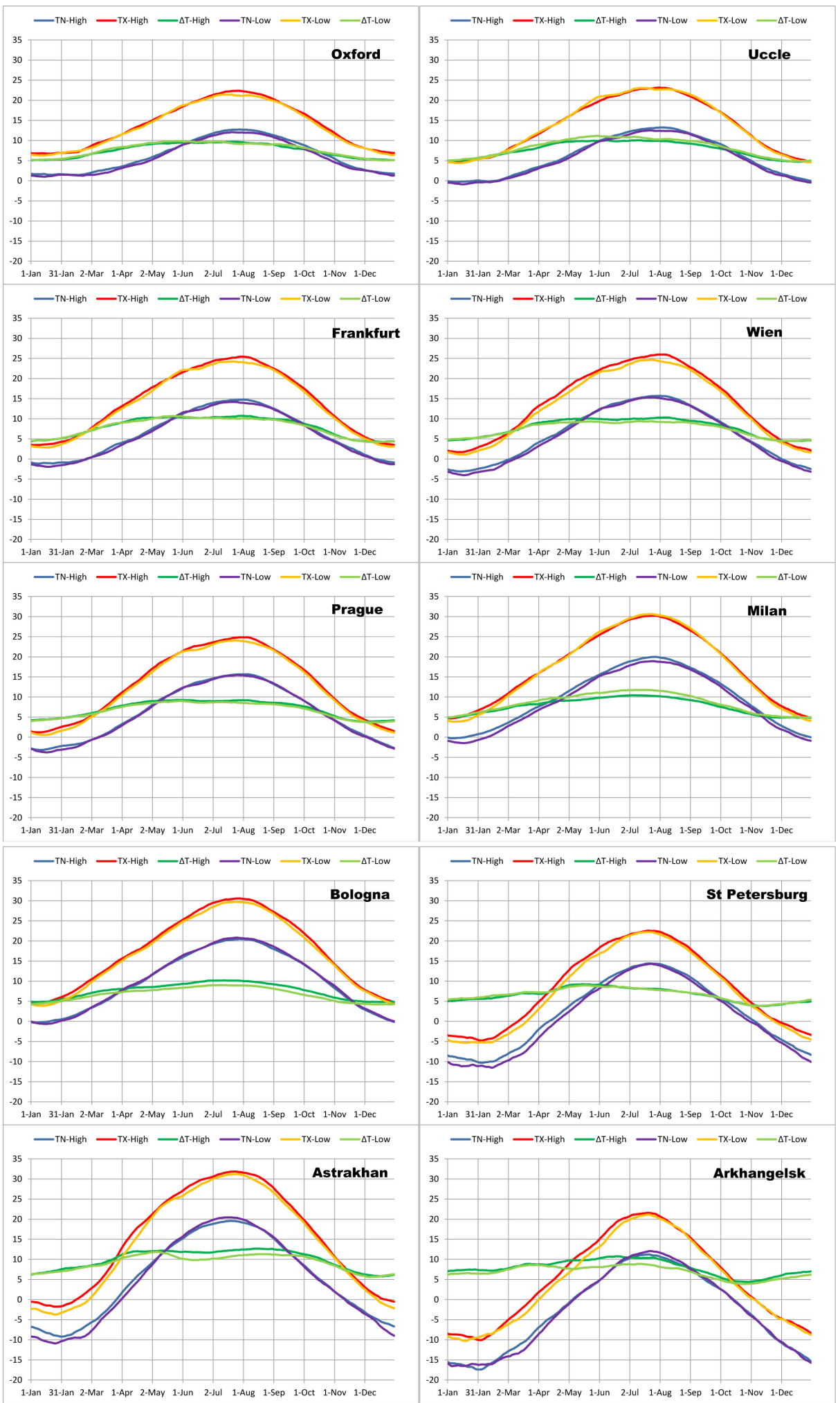

Figure 4. Average annual variation of temperatures (in ${ }^{\circ} \mathrm{C}$ ). For each of the ten European stations ordered by the entropy $\mathrm{H}(\mathrm{TN})$ [8], the red, blue and green curves are for the 21-day centered moving averages of $\mathrm{TN}, \mathrm{TX}$ and $\Delta \mathrm{T}$, respectively, in the periods of high solar activity, while the lighter colors (yellow, light blue and light green) are corresponding temperatures in the periods of low solar activity. 


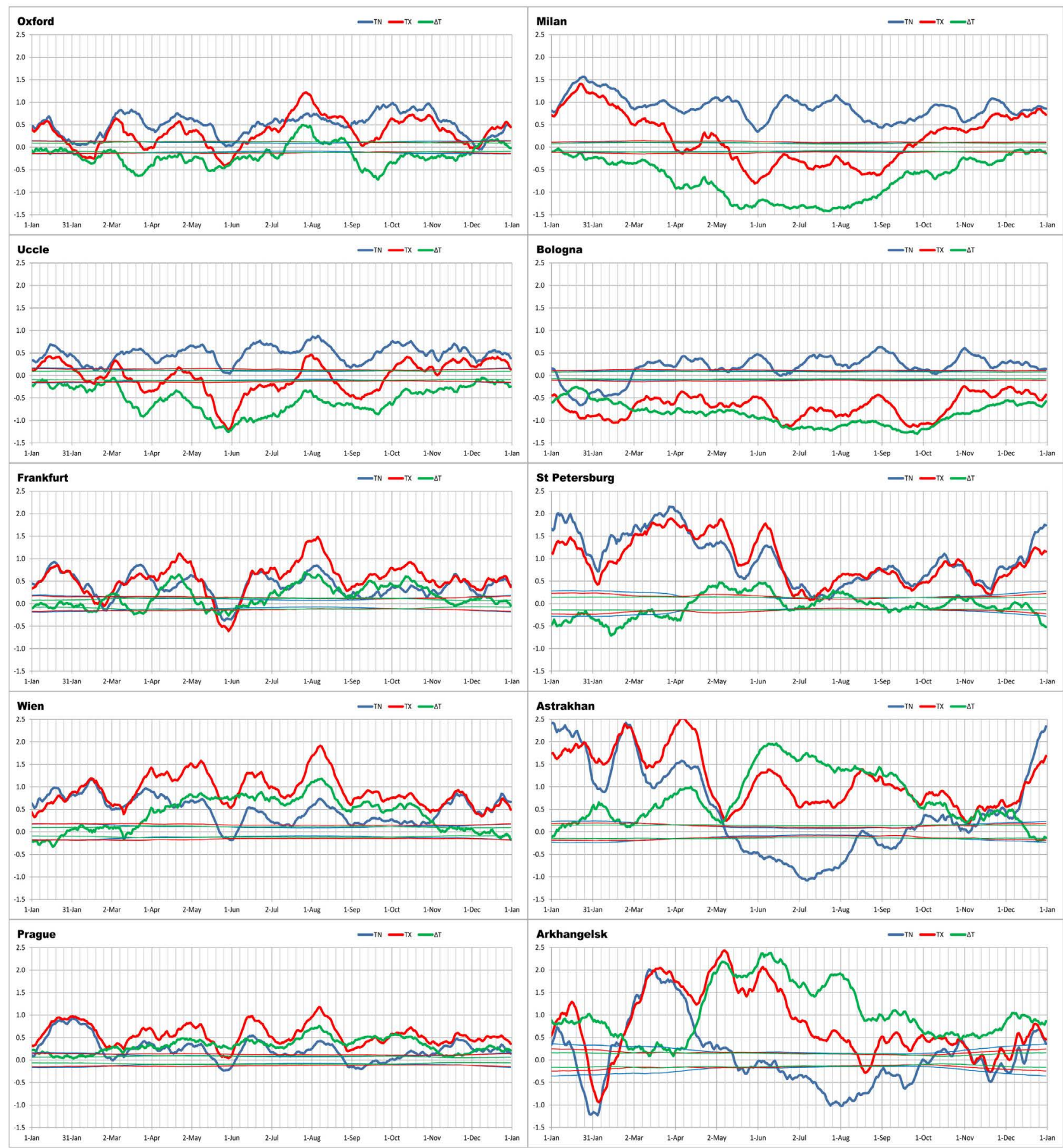

Figure 5. Differences of sample averages between H (high solar activity) and L (low solar activity) times as a function of calendar date (21-day moving averages). For each of the ten European stations blue curves are for TN, red curves for TX and green curves for $\Delta \mathrm{T}$. The ranges of error are given as pairs of thin lines about the 0 axis with the relevant color (see text).

about square root of 21 . In addition, when trying to account for temperature dependencies in 21 days (which we select for averaging), Legras et al. ([3]; page 21, supplementary material) used intervals of 90 and 150 days that are affected by the seasonal variability of temperatures. The autocorrelations of the daily temperatures over 21 days fall below 0.2 in less than 3 days, while on average the 
autocorrelation $^{1}$ for the daily range of temperatures $\Delta \mathrm{T}$ falls below 0.2 on the second day (Figure 6). As a consequence, the T-test results based on the "90-day" dependencies ([3] page 780 and supplementary material) are not relevant [4] [5].

A remarkable and intriguing observation is that curves for TX and TN present quite similar fluctuations between themselves and for most observatories. Figure 7 shows in separate frames for TN, TX and $\Delta \mathrm{T}$ the individual curves for five observatories from the same Cfb climate zone (OXF, UCC, FRA, WIE and PRA, in colours) and their mean (in black). The two mean curves for TN and TX are remarkably similar with oscillations of $\sim 1^{\circ} \mathrm{C}$ in amplitude and $\sim 3$ months (with a 1.5 month "harmonic") in duration. The similarity vanishes when the other five stations, that are more distant and belong to different climate classes, are considered (Figure 8; note that the 10-station mean graphs at the bottom of Figure 8 fit in less than one third of the ordinate range of all curves above). We return to this in the final discussion.

\section{Statistical Tests}

As in [2], we have undertaken statistical comparisons of the $\mathrm{H}$ and L classes, expanding territorial and climatic class coverage of the testing for the patterns of solar impact on Earth's climate.

\subsection{The Two Nonparametric Tests (Kolmogorov-Smirnov and Kuiper Statistics)}

To check whether temperature indices in the solar cycles with high $(\mathrm{H})$ and low $(\mathrm{L})$ activity belong to the same distribution we used the two nonparametric methods, namely, the Kolmogorov-Smirnov [14] [15] and Kuiper [16] [17] tests. These goodness-of-fit tests have the advantage of making no assumption about the distribution of data and, therefore, are widely accepted to be the most useful and general nonparametric methods for comparing two samples. The Kuiper
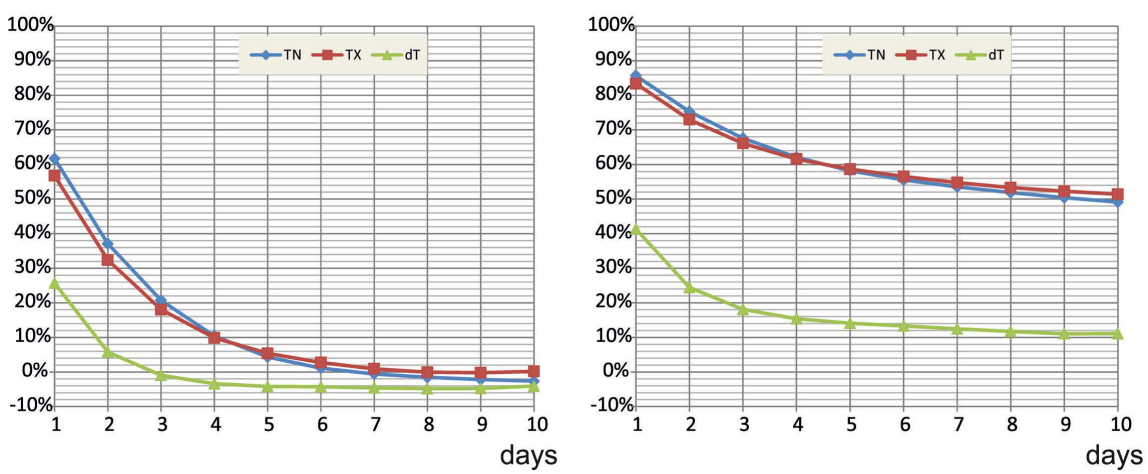

Figure 6. Average autocorrelation function on a 21- (left) and 90-day base (right) at observatory of Milan, 1838-2000. For comments see [4].

\footnotetext{
${ }^{1}$ Autocorrelation function of $\mathrm{T}(\tau)$ is defined as $\mathrm{R}_{\mathrm{T}}(\tau, \mathrm{d} \tau)=\left\langle\mathrm{T}(\tau) \times \mathrm{T}(\tau-\mathrm{d} \tau)>/\left(\sigma_{\mathrm{T}(\tau)} \times \sigma_{\mathrm{T}(\tau-\mathrm{d} \tau)}\right)\right.$, where $<\mathrm{X}(\mathrm{t})>$ and $\sigma_{\mathrm{X}(\mathrm{t})}$ are the average and standard deviation of $\mathrm{X}(\mathrm{t})$; it shows the connection of $\mathrm{T}(\tau)$ with a copy of itself shifted by the value of $\mathrm{d} \tau$.
} 


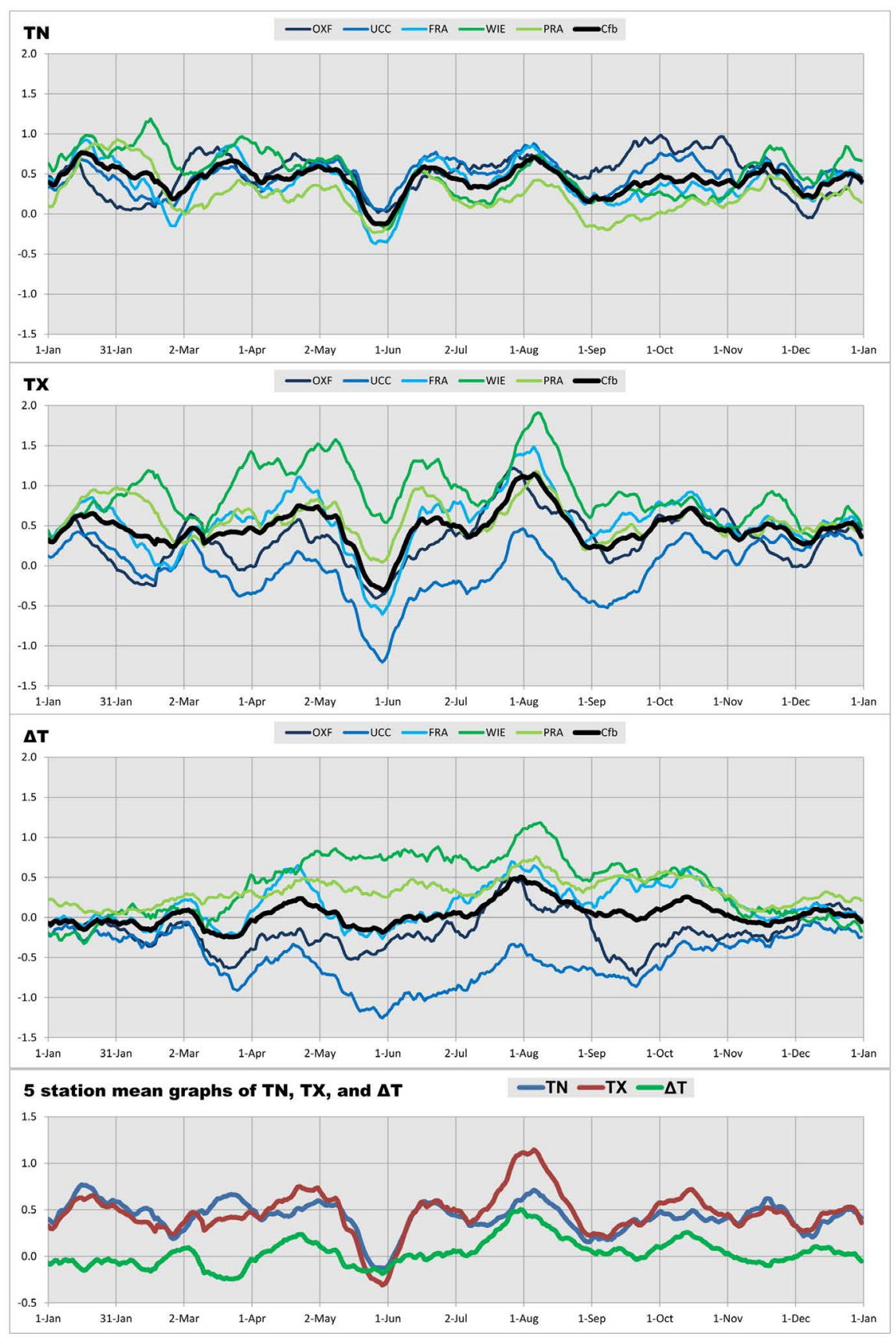

Figure 7. Differences of the TN, TX and $\Delta \mathrm{T}$ sample averages between $\mathrm{H}$ (high solar activity) and L (low solar activity) times as a function of calendar date (21-day moving averages) at five observatories (namely, OXF, UCC, FRA, WIE, PRA) of the same Köppen-Geiger class $(\mathrm{Cfb})$. The black line is the mean of the five station graphs.

test is closely related to the better-known Kolmogorov-Smirnov test that we have used in [1] [2]; however, its invariance under cyclic transformations is of particular value for the data distributed as a function of the Earth's annual cycle.

Consider the empirical probability distribution function $(p d f) F_{n}(x)$ for $\mathrm{n}$ independent identically distributed observations $X_{i}$ defined as $F_{n}(x)=$ \{number of $\left.X_{i} \leq x\right\} / n$. The Kolmogorov-Smirnov $\lambda_{\mathrm{K}-\mathrm{S}}$ and Kuiper $\kappa$ goodness-of-fit statistics 


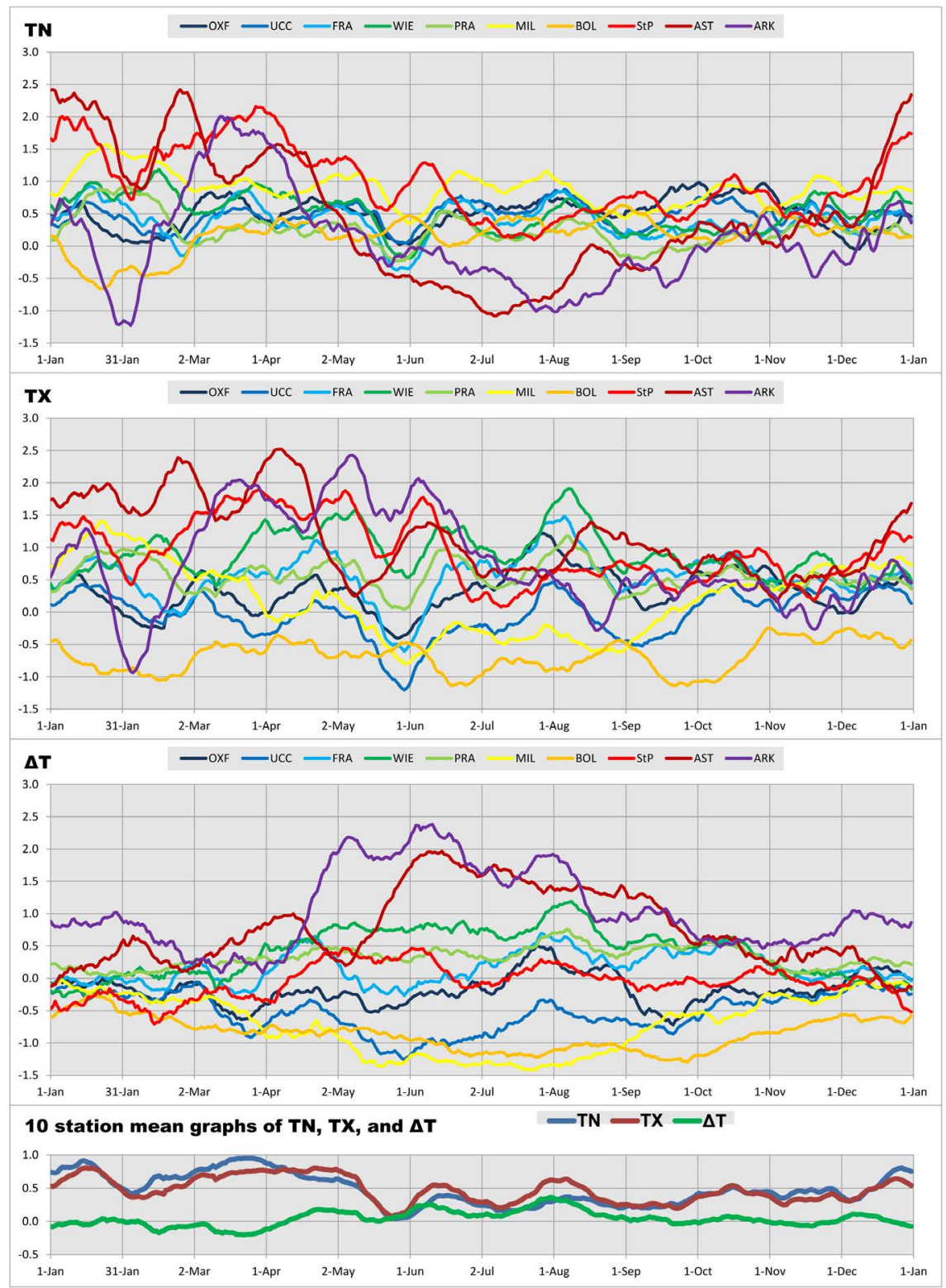

Figure 8. Differences of the TN, TX and $\Delta \mathrm{T}$ sample averages between $\mathrm{H}$ (high solar activity) and L (low solar activity) times as a function of calendar date (21-day moving averages) at the ten European observatories considered and their mean graphs on the bottom plate.

are sensitive to differences in both location and shape of the empirical cumulative distribution functions. The two sample Kolmogorov-Smirnov statistic $\lambda_{\mathrm{K}-\mathrm{S}}$ is defined as

$$
\lambda_{\mathrm{K}-\mathrm{S}}(D, n, m)=[n m /(n+m)]^{1 / 2} D
$$

where $D=\max \left|F_{H, n}(x)-F_{L, n}(x)\right|$ is the maximum value of the absolute difference between the $p d f_{S} F_{H, n}(x)$ and $F_{L, n}(x)$ of the two samples, whose sizes are $n$ and $m$, respectively. The "trick" of the Kuiper test is to consider the difference $V$ $=D^{+}-D^{-}$between the discrepancy statistics $D^{+}=\max \left(F_{H, n}(x)-F_{L, n}(x)\right)$ and 
$D^{-}=\min \left(F_{H, n}(x)-F_{L, n}(x)\right)$ in the definition of $\kappa(D, n, m)=[n m /(n+m)]^{1 / 2} V$. Asymptotically, when $n$ and $m \rightarrow \infty$, the cumulative probability distribution of $\lambda_{\mathrm{K}-\mathrm{S}}$ and $\kappa$ converge to

$$
\operatorname{Prob}\left(\lambda_{\mathrm{K}-\mathrm{S}} \leq x\right)=1-2 \sum_{k=1}^{\infty}(-1)^{k-1} \exp \left(-2 k^{2} x^{2}\right)
$$

and

$$
\operatorname{Prob}(\kappa \leq x)=1-2 \sum_{k=1}^{\infty}\left(4 k^{2} x^{2}-1\right) \exp \left(-2 k^{2} x^{2}\right)
$$

respectively. The null hypothesis is rejected at the significance level $\alpha$, when the probability of exceeding the achieved value of the statistics is less than $\alpha$. Therefore, when using the Kolmogorov-Smirnov or Kuiper tests, the null hypothesis is rejected if $\operatorname{Prob}\left(\lambda_{\mathrm{K}-\mathrm{S}} \leq x\right)>1-\alpha$ or if $\operatorname{Prob}(\kappa \leq x)>1-\alpha$ for either the $\lambda_{\mathrm{K}-\mathrm{S}}$ or $\kappa$ statistics, respectively.

\subsection{Annual Variation of Temperature Indices}

For each temperature index $\mathrm{T}$, we compute the two empirical probability distribution functions $(p d f s) F_{H}(\tau)$ and $F_{L}(\tau)$ as follows: $F_{H}(\tau)$ is the ratio of the number of values of T smaller than $\tau$ to the total number of values for subset $\mathrm{H}$, and, similarly, $F_{L}(\tau)$ is the ratio of the number of values of T smaller than $\tau$ to the total number of values for subset $\mathrm{L}$. The corresponding empirical $p d f s$ for the three temperature indices $\mathrm{TN}, \mathrm{TX}$, and $\Delta \mathrm{T}$ for each of the ten meteorological stations of different Köppen-Geiger classes are given in Figure 9 along with their differences in blue (for TN), red (for TX), and green (for $\Delta \mathrm{T}$ ) in the adjacent plates below the $p d f s$. At the scales of the various parts of the figure, the TN and TX distributions for many stations look similar, but the $\Delta \mathrm{T}$ distribution differences are generally more visible. More precise numerical data pertaining to these distributions are given in Table 2. Whether the various distributions are actually numerically distinct or not requires calling upon the Kolmogorov-Smirnov two-sample criterion as done in our previous papers. We recall that the KS two-sample test is a form of minimum distance estimate used as a nonparametric test to check if the samples are drawn from the same distribution.

Table 2 summarizes the test results in terms of $\lambda_{\mathrm{K}-\mathrm{S}}$ (for the purpose of further comparison, we distinguish, by different shading of the corresponding cell, whether the largest absolute difference of $\left(F_{H}(\tau)-F_{L}(\tau)\right)$ is positive or negative).

We see that $\lambda_{\mathrm{K}-\mathrm{S}}$ values are larger to much larger than the standard critical value of 1.36 (corresponding to the confidence level of 95\%) for all distributions. These results, however, cannot be expressed directly in terms of probability because the hypothesis that the two populations of $\mathrm{T}$ temperature values in the two classes $H$ and $L$ are drawn from the same statistical distribution of independent variables does not hold, due to clear dependencies, such as the annual variation of temperature. A multiple parameter criterion helps to improve our ability to discriminate an "unusual" partition of data into physically justified classes (here $\mathrm{H}$ and $\mathrm{L}$ ) among more "common" randomly sampled ones. A randomized 

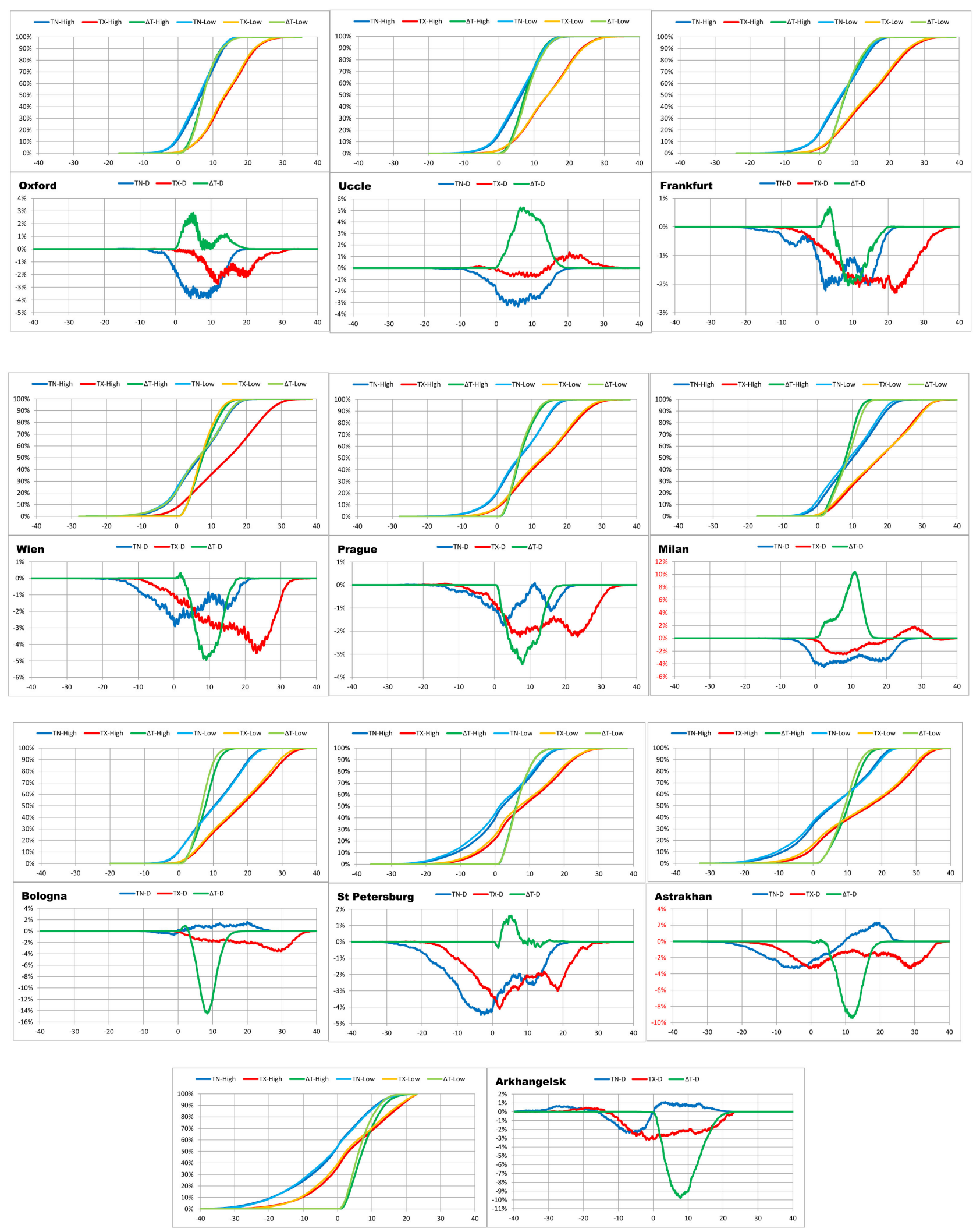

Figure 9. Empirical probability distribution functions $F_{H}(\tau)$ and $F_{L}(\tau)$ for the daily minimum temperature TN, daily maximum temperature TX and daily temperature range $\Delta \mathrm{T}$ in the periods of high and low solar activity at the ten European stations. Except for Arkhangelsk, the differences $D(\tau)=F_{H}(\tau)-F_{L}(\tau)$ are plotted below each set of $p d f$. 
Table 2. The Kolmogorov-Smirnov test $\lambda_{\mathrm{K}-\mathrm{S}}$ statistics and criteria tests for TN, TX, and $\Delta \mathrm{T}$ temperature indices. Notes: The $\lambda$-values on blue mean higher temperature index in the times of high solar activity. $\mathrm{C} 1-\max \left(\lambda_{\mathrm{TN}}, \lambda_{\mathrm{TX}}, \lambda_{\Delta \mathrm{T}}\right)>\lambda$; $\mathrm{C} 2-\lambda_{\mathrm{TN}}>\lambda$; $\mathrm{C} 3-\lambda_{\mathrm{TX}}>\lambda$; $\mathrm{C} 4-\lambda_{\Delta \mathrm{T}}>\lambda$; C5- $\left(\lambda_{\mathrm{TN}}>\lambda_{1}, \lambda_{\mathrm{TX}}>\lambda_{2}, \lambda_{\Delta \mathrm{T}}>\lambda_{3}\right)$. The numbers of outscores in 1000 random shuffles implying statistical significance level below $5 \%$ (i.e. confidence above $95 \%$ ) are given in bold on pink background.

\begin{tabular}{ccccccccc}
\hline Station & $\lambda \mathrm{TN}$ & $\lambda \mathrm{TX}$ & $\lambda \Delta \mathrm{T}$ & $\mathrm{C1}$ & $\mathrm{C} 2$ & $\mathrm{C} 3$ & $\mathrm{C} 4$ & $\mathrm{C5}$ \\
\hline Oxford (UK) & 4.49 & 3.17 & 3.32 & 67 & 15 & 98 & 222 & 5 \\
\hline Uccle (Belgium) & 4.18 & 1.66 & 6.48 & 124 & 44 & 695 & 124 & 14 \\
\hline Frankfurt (Germany) & 2.68 & 2.58 & 2.10 & 519 & 200 & 229 & 578 & 86 \\
\hline Wien (Austria) & 3.40 & 5.30 & 5.77 & 77 & 95 & 20 & 77 & 6 \\
\hline Prague (Czech Republic) & 2.56 & 3.24 & 4.99 & 156 & 410 & 147 & 141 & 19 \\
\hline Milan (Italy) & 5.64 & 3.13 & 12.85 & 27 & 124 & 420 & 27 & 11 \\
\hline Bologna (Italy) & 2.15 & 4.62 & 18.96 & 38 & 602 & 84 & 38 & 20 \\
\hline St Petersburg (Russian Federation) & 4.84 & 4.43 & 1.72 & 30 & 23 & 1 & 548 & 1 \\
\hline Astrakhan (Russian Federation) & 3.49 & 3.50 & 9.86 & 23 & 45 & 115 & 23 & 0 \\
\hline Arkhangelsk (Russian Federation) & 2.66 & 3.59 & 10.56 & 4 & 194 & 16 & 4 & 0 \\
\hline
\end{tabular}

sample is generated by a shuffle of solar cycles that preserves all temperature dependences within a cycle while destroying their affiliation to classes of high and low solar activity. As part of this randomization of temperature indices at each observatory, we have calculated 1000 triplets $\left(\lambda_{\mathrm{TN}}, \lambda_{\mathrm{TX}}, \lambda_{\Delta \mathrm{T}}\right)$ of the Kolmogorov-Smirnov $\lambda_{\mathrm{K}-\mathrm{S}}$ statistics linked to (TN, TX, $\Delta \mathrm{T}$ ). There are many possibilities to measure the separation of classes in such multidimensional data. The comparison of the temperature data partitions can be performed using the maximum of the three statistics $\left(\lambda_{\mathrm{TN}}, \lambda_{\mathrm{TX}}, \lambda_{\Delta \mathrm{T}}\right)$; it may then be governed in the range of high values by a single parameter. Another criterion can be any of the three individual criteria $\lambda_{\mathrm{TN}}>\lambda$ or $\lambda_{\mathrm{TX}}>\lambda$ or $\lambda_{\Delta \mathrm{T}}>\lambda$. A more complete and stringent criterion requires domination in each of the three $\lambda_{\mathrm{K}-\mathrm{S}}$ statistics $\left(\lambda_{\mathrm{TN}}>\right.$ $\lambda_{1}, \lambda_{\mathrm{TX}}>\lambda_{2}, \lambda_{\Delta \mathrm{T}}>\lambda_{3}$ ), where $\lambda_{1}, \lambda_{2}$, and $\lambda_{3}$ are given constants (e.g., the values relevant to the $\mathrm{H}$ vs $\mathrm{L}$ splitting). The proportion of random drawings which outscore the $\lambda_{\mathrm{K}-\mathrm{S}}$ statistics of the physically determined partition provides an adequate estimate of its statistical significance. Table 2 sums up the results of random shuffling of cycles, which allow us to compare different partitions of the temperature data by any of the five criteria: $\mathrm{C} 1-\max \left(\lambda_{\mathrm{TN}}, \lambda_{\mathrm{TX}}, \lambda_{\Delta \mathrm{T}}\right)>\lambda$; $\mathrm{C} 2-\lambda_{\mathrm{TN}}>\lambda$; $\mathrm{C} 3-\lambda_{\mathrm{TX}}>\lambda$; $\mathrm{C} 4-\lambda_{\Delta \mathrm{T}}>\lambda$; $\mathrm{C} 5-\left(\lambda_{\mathrm{TN}}>\lambda_{1}, \lambda_{\mathrm{TX}}>\lambda_{2}, \lambda_{\Delta \mathrm{T}}>\lambda_{3}\right)$.

For example, for minimum temperature TN at Milan, 124 random drawings (i.e. $12.4 \%)$ outscore the $(\mathrm{H}, \mathrm{L})$ partition using the simplest individual criterion with $\lambda_{\mathrm{TN}}$ alone (Table 2, sixth row). The $\max \left(\lambda_{\mathrm{TN}}, \lambda_{\mathrm{TX}}, \lambda_{\Delta \mathrm{T}}\right)$ criterion scores 27 , i.e. about $2.7 \%$, as an estimate of significance level. The criterion C5 that combines limitations on triplets of the Kolmogorov-Smirnov statistics $\left(\lambda_{\mathrm{TN}}, \lambda_{\mathrm{TX}}, \lambda_{\Delta \mathrm{T}}\right)$ finds only 11 outscores; hence, the statistical significance level is about $1 \%$ and indicates that temperature series and solar activity are related with a confidence 
on the order of $99 \%$. As usual, the Kolmogorov-Smirnov statistics can also be considered as a "goodness of fit" test, in which in a way criterion C5 is the dual of criterion $\mathrm{C} 1$ (in one case points are close to the origin, in the other they are the most remote). The larger the number of outscores in $\mathrm{C} 1$, the better the fit of the two samples subjected to the test. The statistics of the combined $\left(\lambda_{\mathrm{TN}}, \lambda_{\mathrm{TX}}\right.$, $\lambda_{\Delta \mathrm{T}}$ ) criterion (i.e., Table 2 , column C5) ranges from 0 to 20 outscores at nine out of the ten European observatories (except for 86 outscores at Frankfurt), implying confidence levels of about $98 \%$ or higher (and 91\%, respectively). These results argue strongly for the presence of a signature of solar activity in all temperature data. We have performed similar analyses on the absolute values of the first derivatives of the temperature indices (as done in [2], results are shown in Table 3). As in our earlier paper, combining the analyses on temperatures and temperature derivatives further raises the confidence for claiming a distinctive solar influence in nine European station temperatures above the $99.5 \%$ level and 94.4\% in Frankfurt.

\subsection{Redistribution of the Temperature Indices in the Low, Middle, and High Quartiles}

For each temperature index $\mathrm{T}$, we define three classes corresponding to the 1 st (low), 2nd and 3rd (middle), and 4th (high) quartiles of the observed values of T. For each of the three classes we first subdivide it into subsets $\mathrm{H}$ and $\mathrm{L}$ (defined in Section 4.2 above), then compute $F_{H}(\Delta)$ and $F_{L}(\Delta)$ as follows: $F_{H}(\Delta)$ is the number of dates in subset $\mathrm{H}$ from the beginning of the year to the date $\Delta$ divided by the total number of dates in subset $\mathrm{H}$, and, similarly, $F_{L}(\Delta)$ is the number of dates in subset $\mathrm{L}$ from the beginning of the year to the date $\Delta$ divided by the total

Table 3. The Kolmogorov-Smirnov test $\lambda_{\mathrm{K}-\mathrm{S}}$ statistics and criteria tests for TN, TX, $\Delta \mathrm{T}$, $\mathrm{dTN} / \mathrm{dt}, \mathrm{dTX} / \mathrm{dt}$, and $\mathrm{d} \Delta \mathrm{T} / \mathrm{dt}$ temperature indices. Notes: Criteria $\mathrm{C}^{*}$ and $\mathrm{C}^{*}$ correspond to $\max \left(\lambda_{\mathrm{TN}}, \lambda_{\mathrm{TX}}, \lambda_{\Delta \mathrm{T}}, \lambda_{\mathrm{dTN} / \mathrm{dt}}, \lambda_{\mathrm{dTX} / \mathrm{dt},}, \lambda_{\mathrm{d} \Delta \mathrm{T} / \mathrm{dt}}\right)$ and the combined six Kolmogorov-Smirnov statistics $\left(\lambda_{\mathrm{TN}}, \lambda_{\mathrm{TX}}, \lambda_{\Delta \mathrm{T}}, \lambda_{\mathrm{dTN} / \mathrm{dt}}, \lambda_{\mathrm{dTX} / \mathrm{dt}}, \lambda_{\mathrm{d} \Delta \mathrm{T} / \mathrm{dt}}\right)$. The numbers of outscores in 1000 random shuffles implying statistical significance level below $5 \%$ (i.e. confidence above $95 \%$ ) are given in bold on pink background.

\begin{tabular}{ccccccccc}
\hline Station & $\lambda_{\mathrm{TN}}$ & $\lambda_{\mathrm{TX}}$ & $\lambda_{\Delta \mathrm{T}}$ & $\lambda_{\mathrm{dTN} / \mathrm{dt}}$ & $\lambda_{\mathrm{dTX} / \mathrm{dt}}$ & $\lambda_{\mathrm{d} \Delta \mathrm{T} / \mathrm{dt}}$ & $\mathrm{C1}^{*}$ & $\mathrm{C5}^{*}$ \\
\hline Oxford (UK) & 4.49 & 3.17 & 3.32 & 1.91 & 1.84 & 2.91 & 154 & $\mathbf{5}$ \\
\hline Uccle (Belgium) & 4.18 & 1.66 & 6.48 & 4.47 & 1.43 & 0.95 & 231 & $\mathbf{1}$ \\
\hline Frankfurt (Germany) & 2.68 & 2.58 & 2.10 & 0.67 & 0.59 & 1.83 & 530 & 56 \\
\hline Wien (Austria) & 3.40 & 5.30 & 5.77 & 1.53 & 2.70 & 2.06 & 77 & $\mathbf{1}$ \\
\hline Prague (Czech Republic) & 2.56 & 3.24 & 4.99 & 4.73 & 1.53 & 2.24 & 174 & $\mathbf{7}$ \\
\hline Milan (Italy) & 5.64 & 3.13 & 12.85 & 2.47 & 3.08 & 0.62 & $\mathbf{2 7}$ & $\mathbf{5}$ \\
\hline Bologna (Italy) & 2.15 & 4.62 & 18.96 & 1.40 & 9.99 & 10.40 & $\mathbf{3 8}$ & $\mathbf{0}$ \\
\hline St Petersburg (Russian Federation) & 4.84 & 4.43 & 1.72 & 1.10 & 2.57 & 1.58 & $\mathbf{3 0}$ & $\mathbf{0}$ \\
\hline Astrakhan (Russian Federation) & 3.49 & 3.50 & 9.86 & 5.11 & 3.44 & 3.31 & $\mathbf{2 3}$ & $\mathbf{0}$ \\
\hline Arkhangelsk (Russian Federation) & 2.66 & 3.59 & 10.56 & 5.24 & 4.45 & 3.75 & $\mathbf{4}$ & $\mathbf{0}$ \\
\hline
\end{tabular}


number of dates in subset $\mathrm{L}$. The corresponding pairs of empirical $p d f$ for the three temperature indices $\mathrm{TN}, \mathrm{TX}$, and $\Delta \mathrm{T}$ and three classes of low, middle, and high ranges of $\mathrm{T}$ are given in Figure 10. For each of the ten European stations the differences $D(\Delta)=F_{H}(\Delta)-F_{L}(\Delta)$ are plotted in black. Figure 11 shows the full range of the $D(\Delta)$ graphs for the ten European stations, reflecting among other things the diversity of climate zones. Even with only the five European meteorological stations in the same Köppen-Geiger climate class Cfb and despite some similar patterns, we observe significant differences in the preferred times of low, middle, and high temperatures in the sequences of cycles with either high or low solar activity.

For example, in the case of Milan (Figure 10) the shift from November-December to January-March of low temperature extremes of TN indicates is strongly significant, whereas for TX it appears insignificant (Table 4). The "pulses" of statistically very highly significant redistributions of middle and high temperature values of TN and TX show up as shifts from August-December to January-July and from June-September to April-May, respectively. These coherent redistributions of TN and TX result in statistically significant changes of $\Delta \mathrm{T}$, with $\alpha$ 's below $0.01 \%$. Figure 11 and Figure 12 suggest a number of quite different scenarios of response to durable solar forcing at locations of the ten European observatories.

\subsection{Redistribution of the Air-Pressure Index PP in the Low, Middle, and High Quartiles}

For each of the three observatories with very long records of the ECA \& D Sea level pressure index PP shown in Figure 13 (170 years at De Bilt, 151 years at Armagh, and 127 years at Paris-Montsouris), we applied exactly the same procedures as in Section 4.3. The corresponding pairs of empirical pdfs for the air-pressure index PP and its three classes of low, middle, and high values are given in Figure 14. The Kuiper test statistics are summarized in Table 5. We see no indication of significant differences in the air-pressure distributions of the middle range of PP at the three observatories. On the contrary, in the low and high ranges of pressure the confidence level of $95 \%$ is exceeded in five out of six

cases; specifically, in the high range, the Kuiper test rejects the null hypothesis of the same distribution in the solar cycles of high versus low activity with confidence about $99 \%$ or higher for all three observatories, same as for the low range of the ECA \& D longest PP series of station De Bilt. The lower row in Figure 9 shows that there are many similarities between curves from the three observatories, further evidencing the regional effects that are NOT concealed by noise.

\section{Discussion and Conclusion}

In this paper, we have demonstrated that splitting long series of daily temperature data according to the level of solar activity reveals rather large are consistent variations of the annual average temperatures (Figure 5, Figure 7, and 

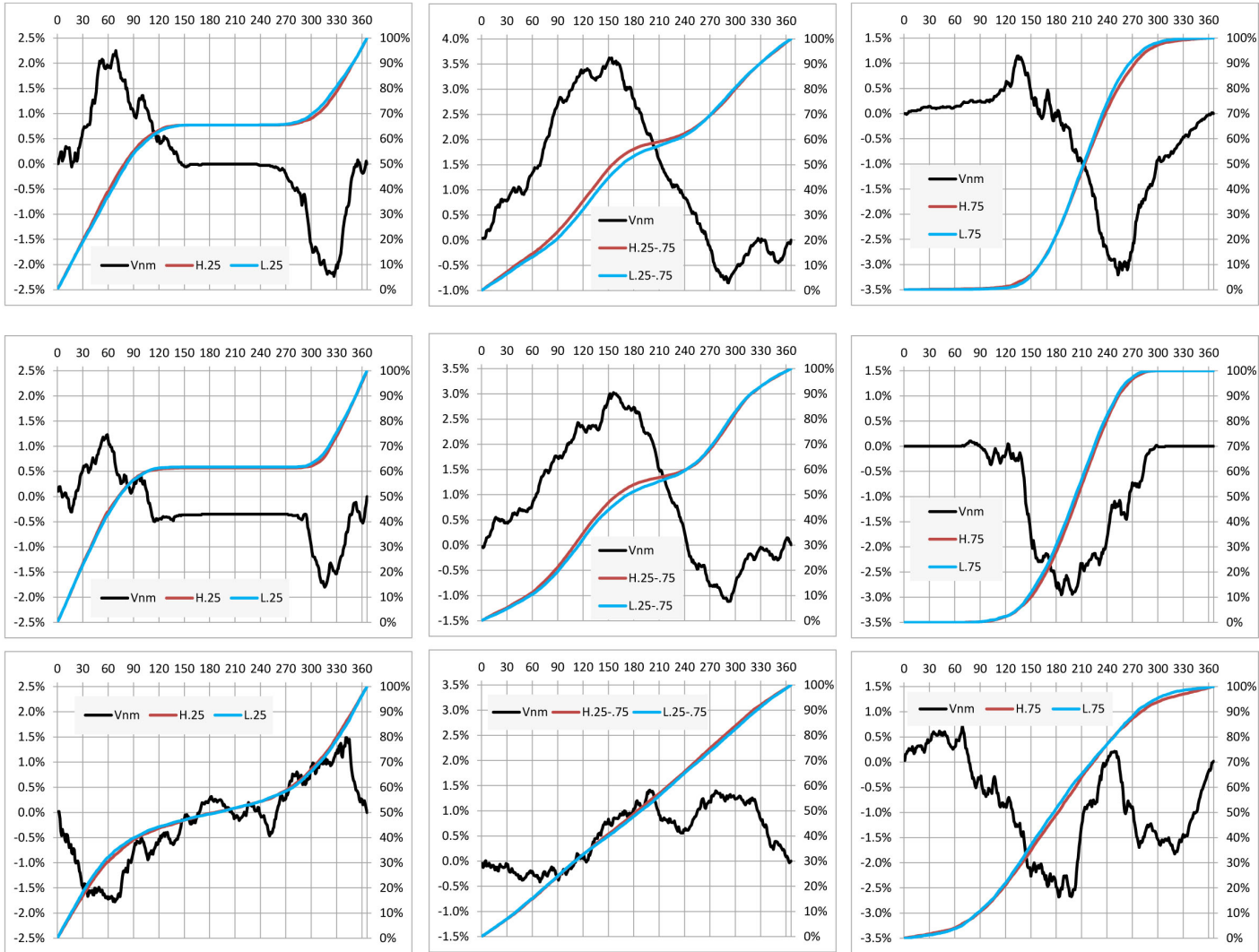

Uccle (Belgium)
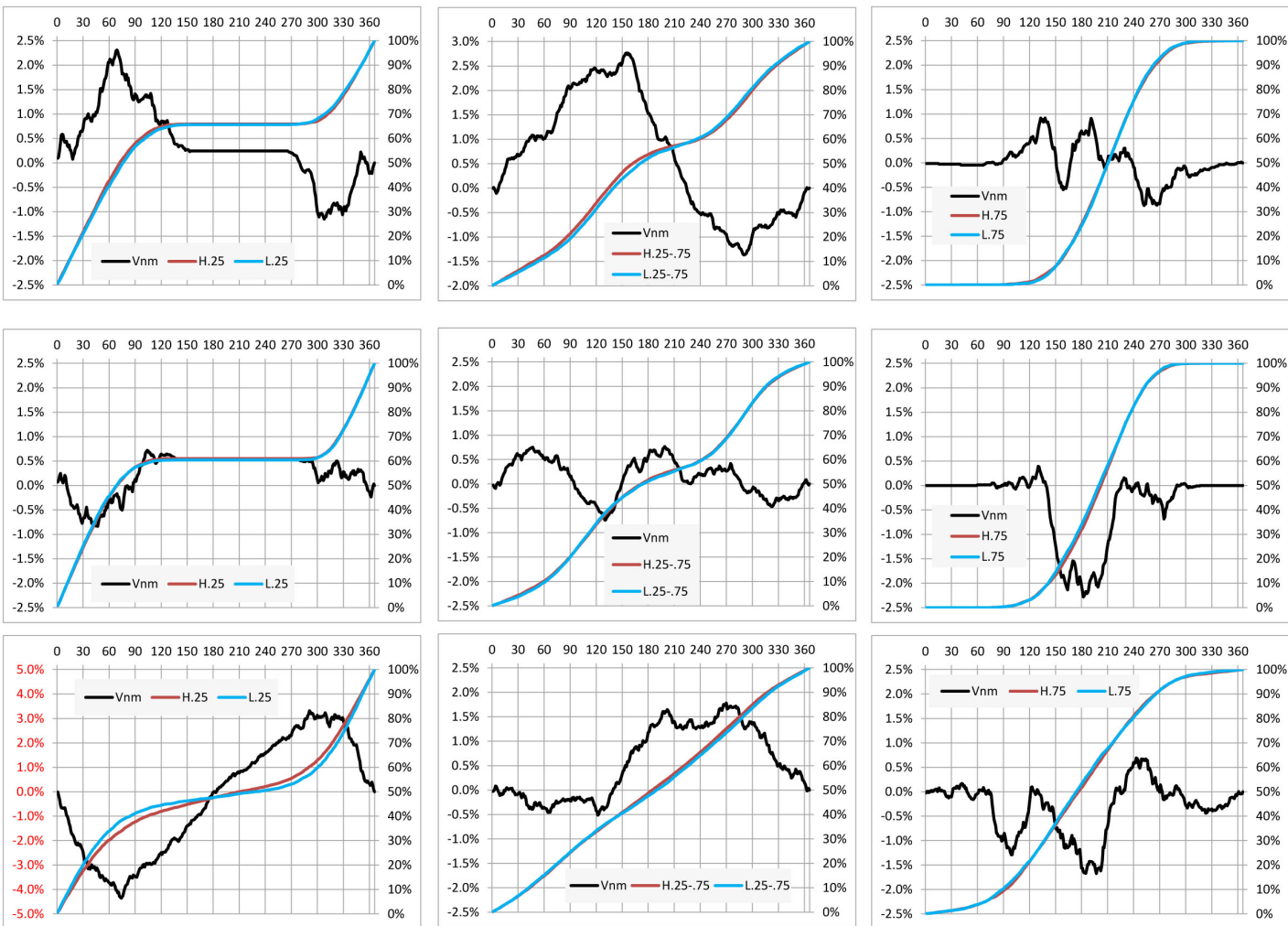
Frankfurt (Germany)
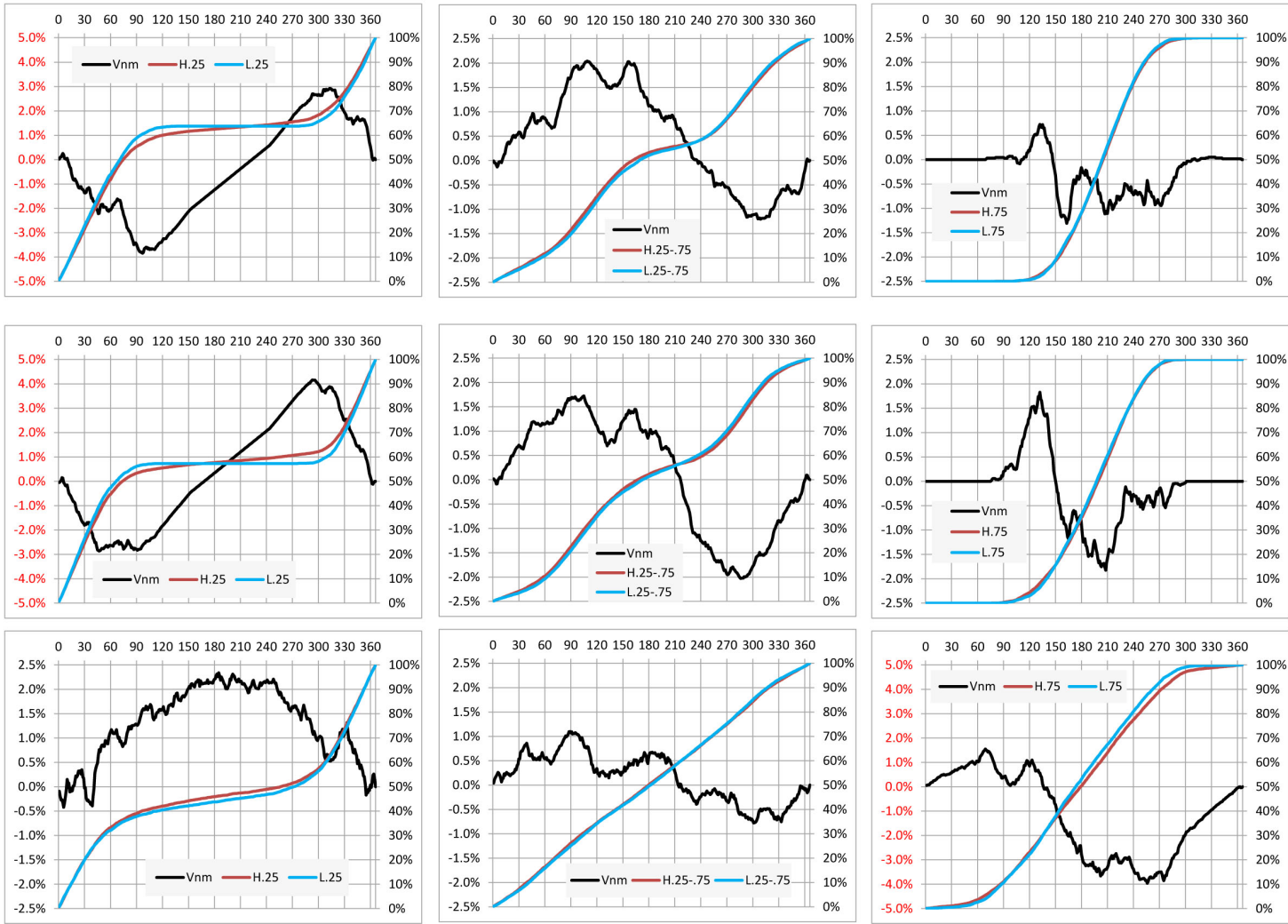

Wien (Austria)
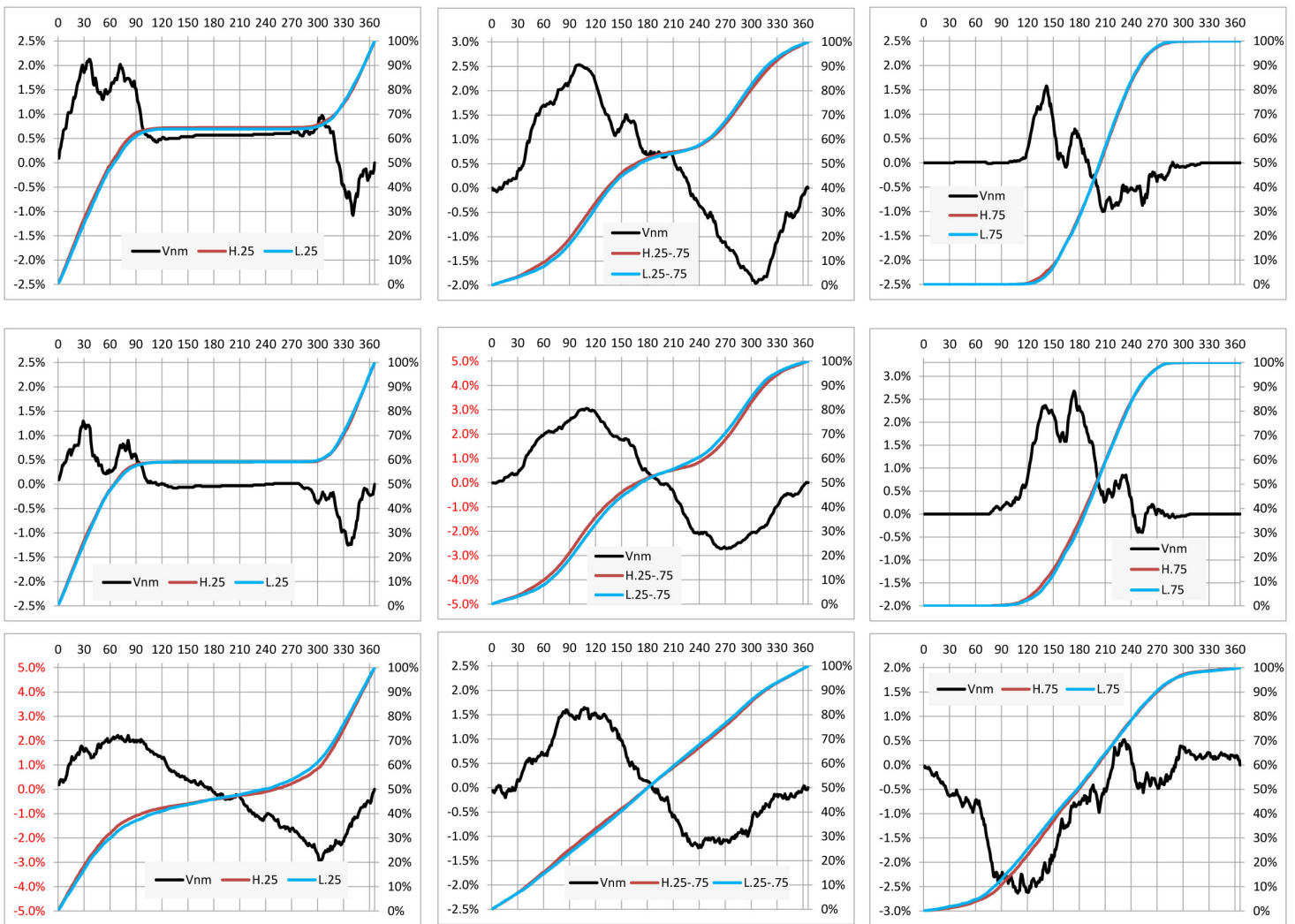
Prague (Czech Republic)
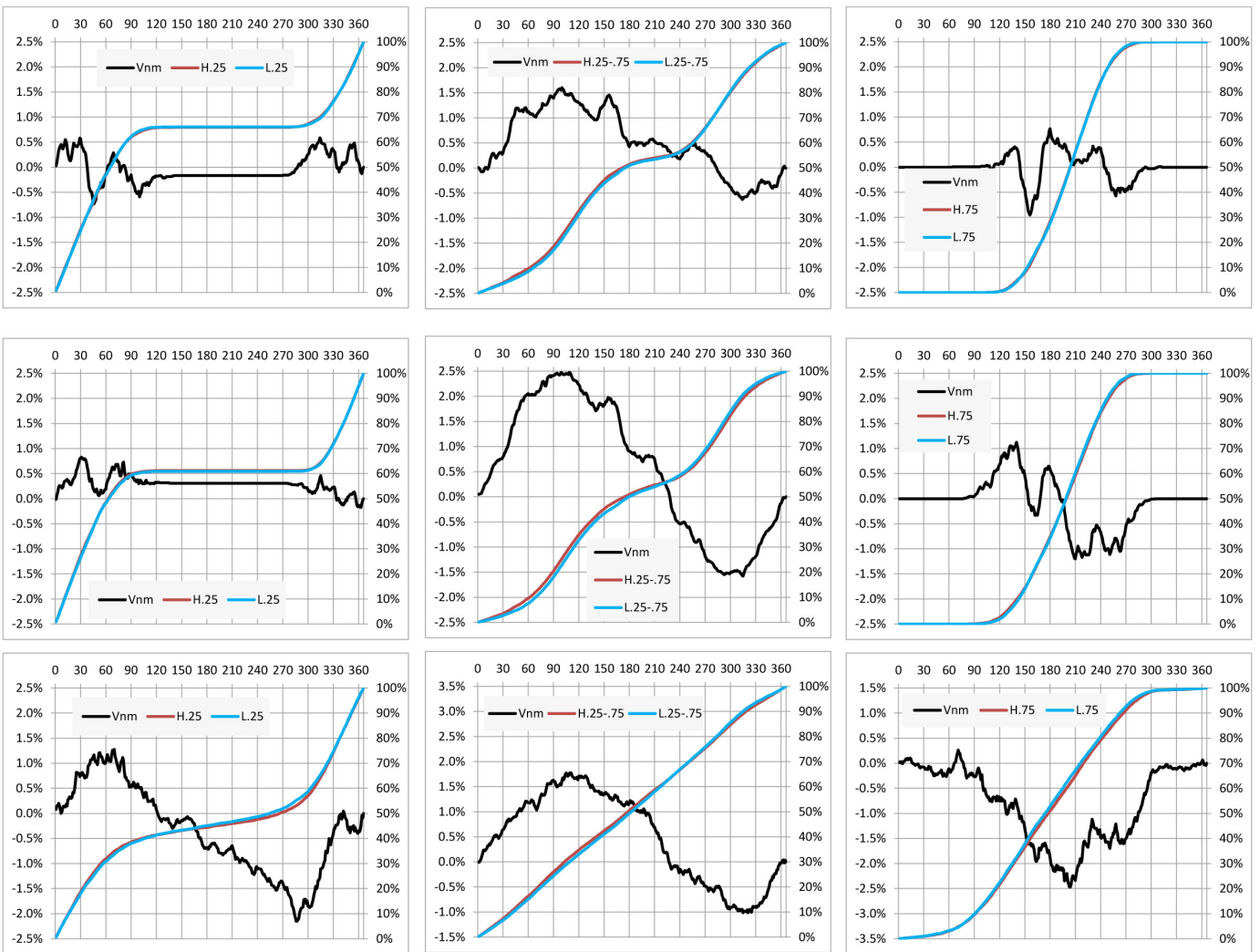

\section{Milan (Italy)}
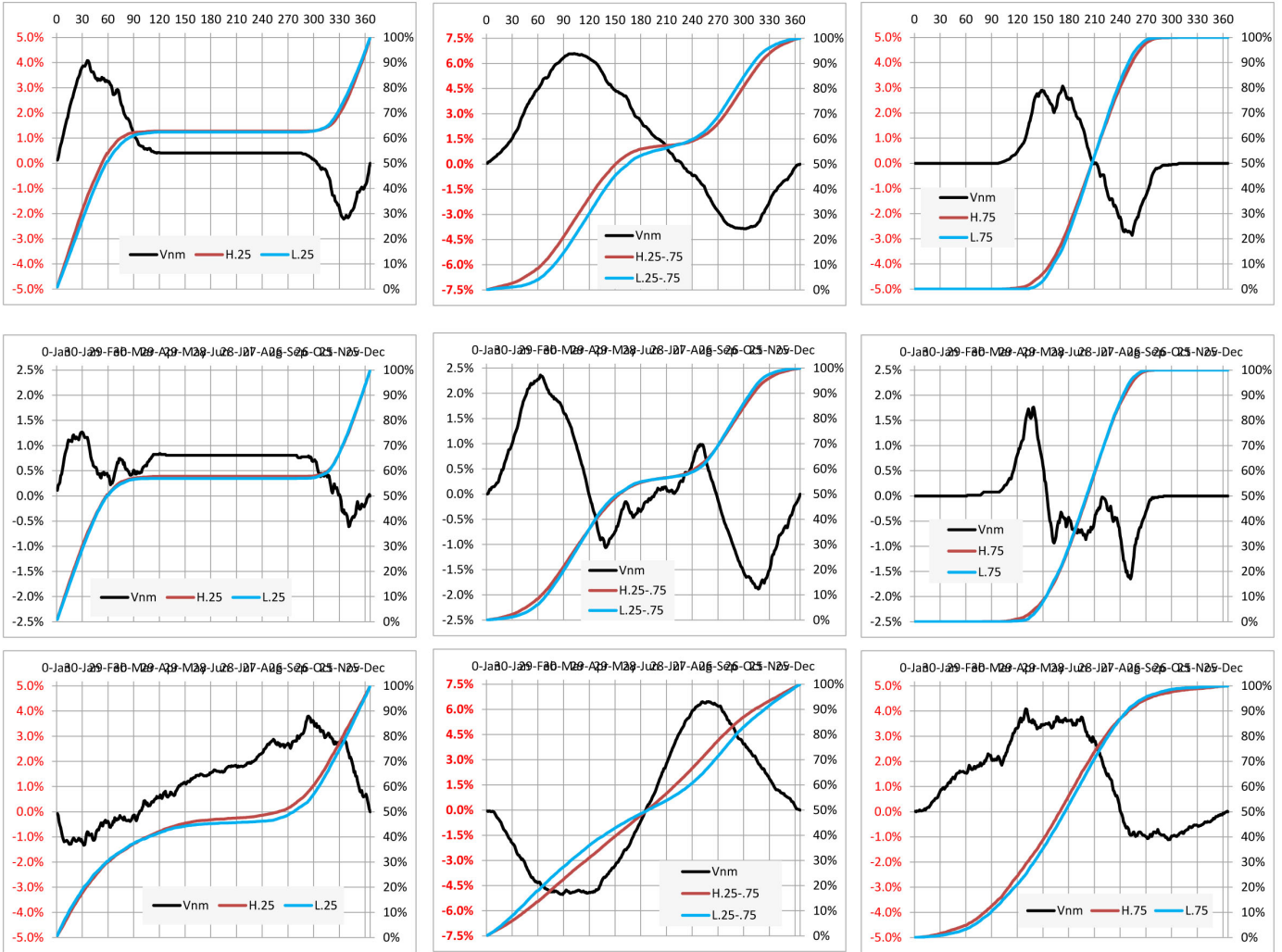
Bologna (Italy)
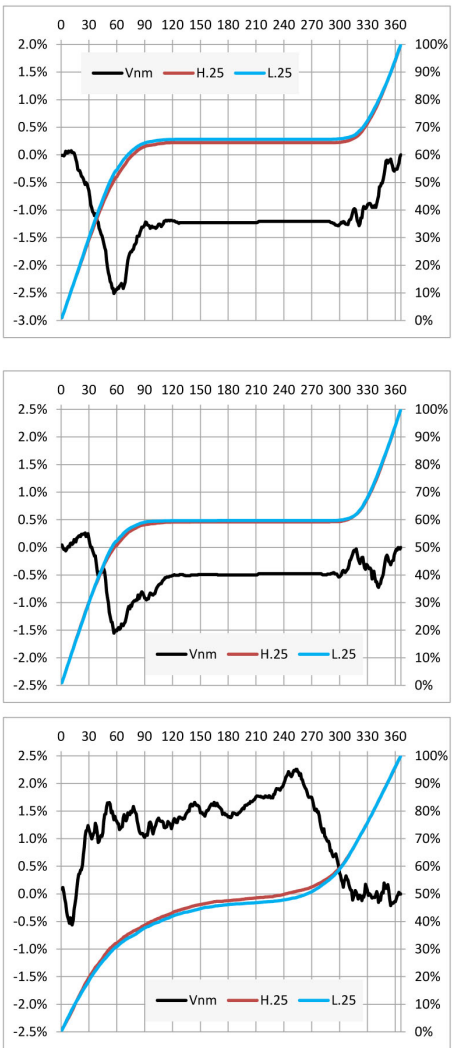
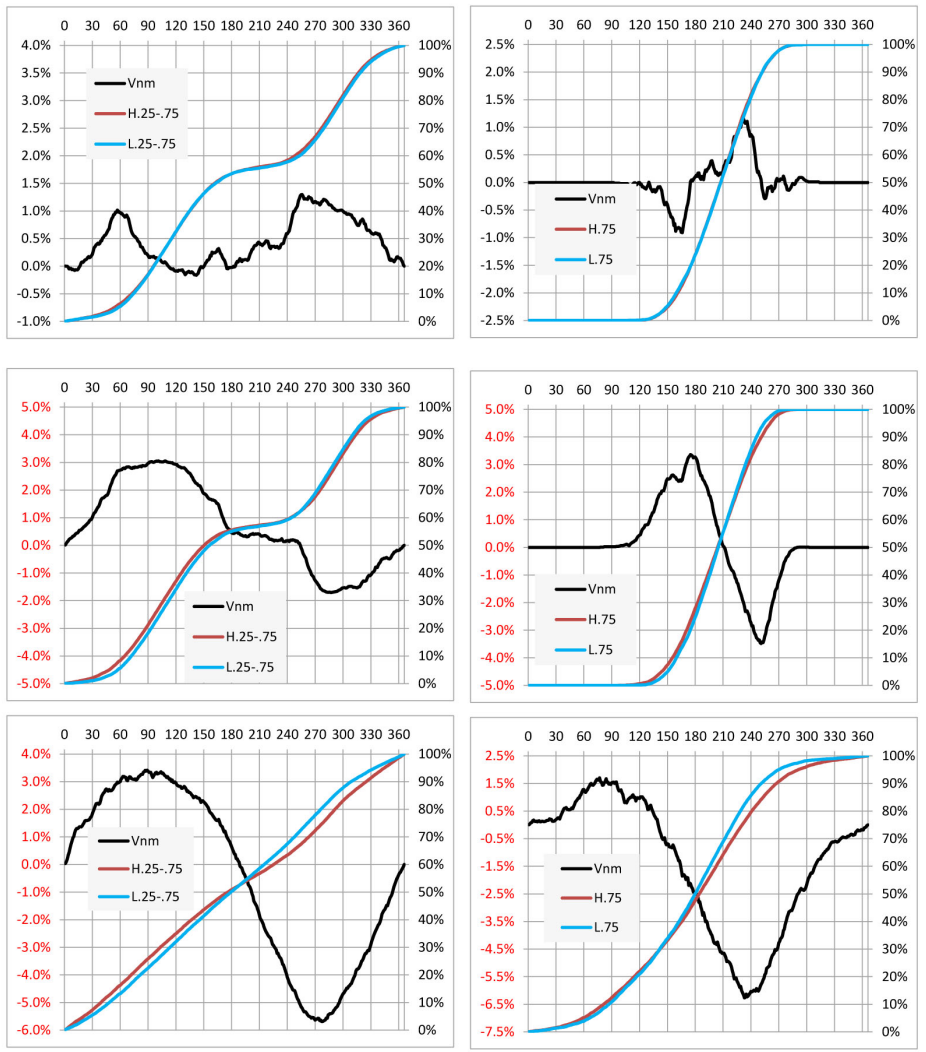

St Petersburg (Russian Federation)
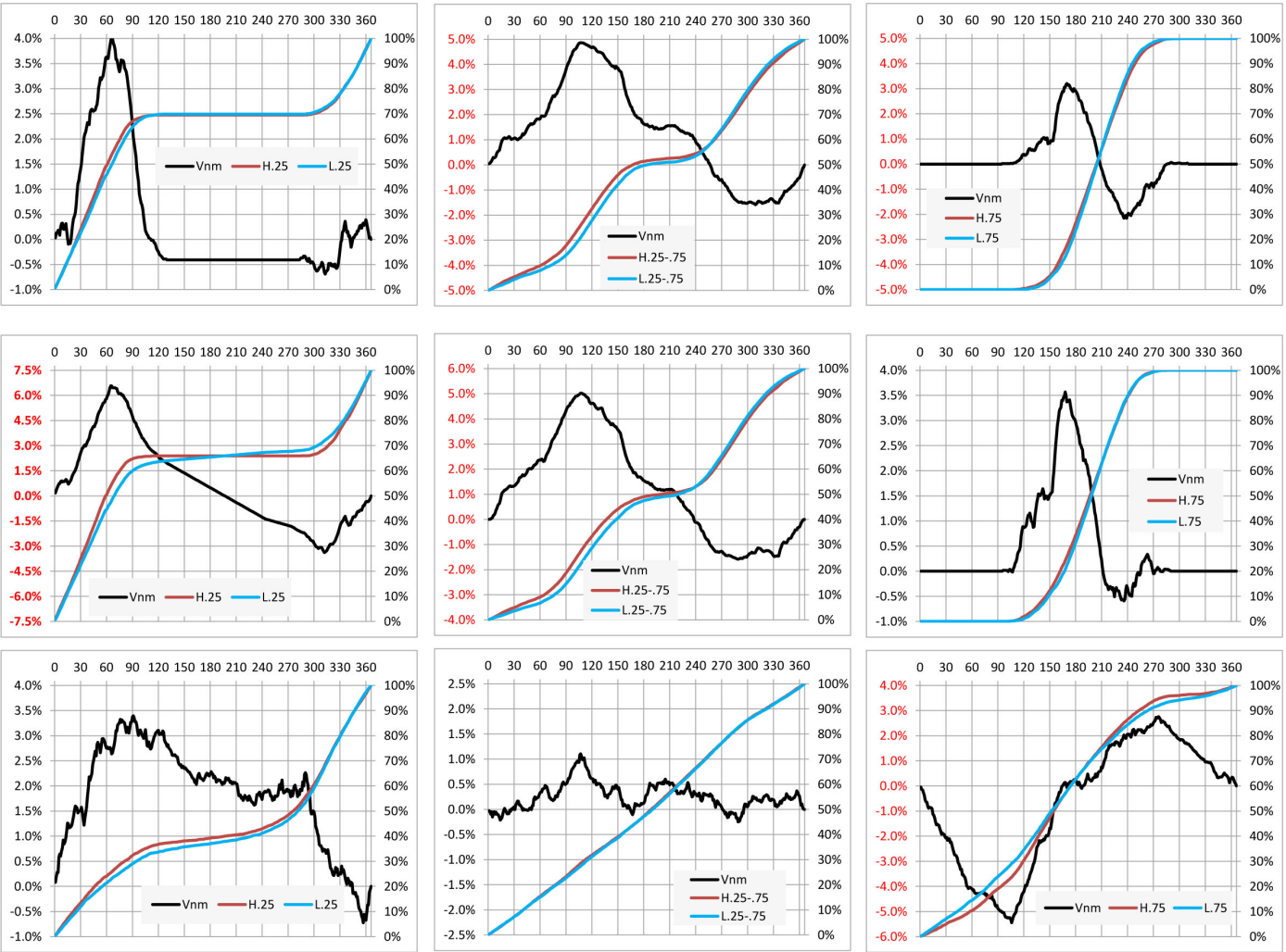


\section{Astrakhan (Russian Federation)}
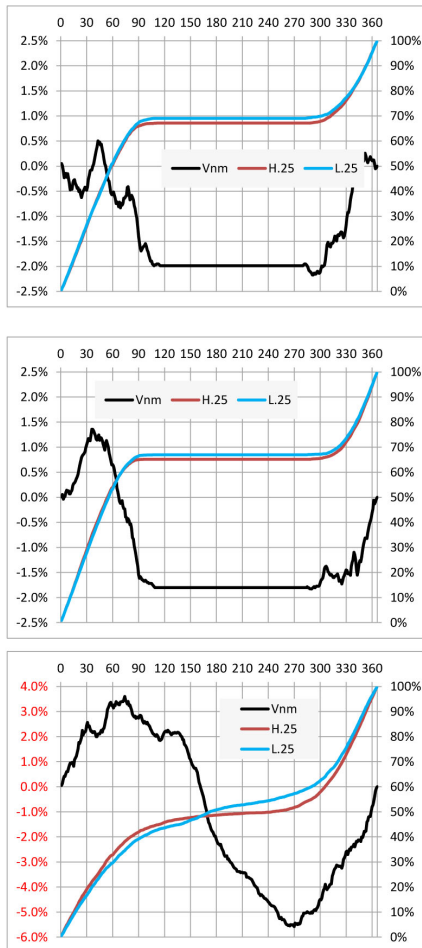
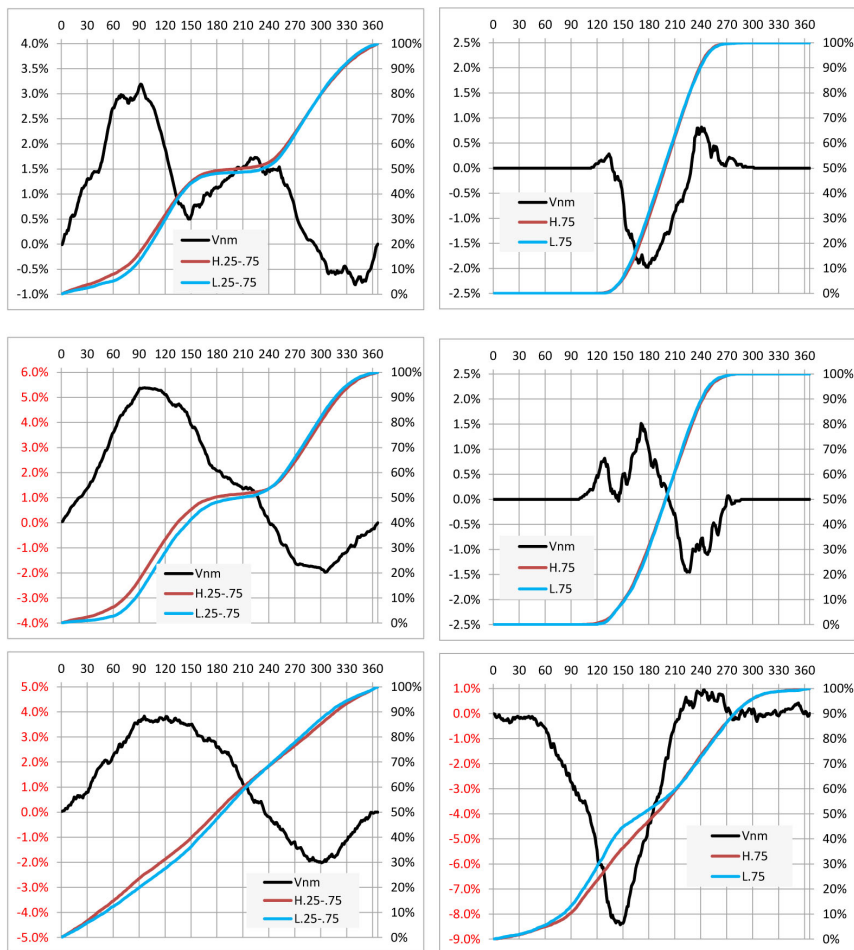

\section{Arkhangelsk (Russian Federation)}
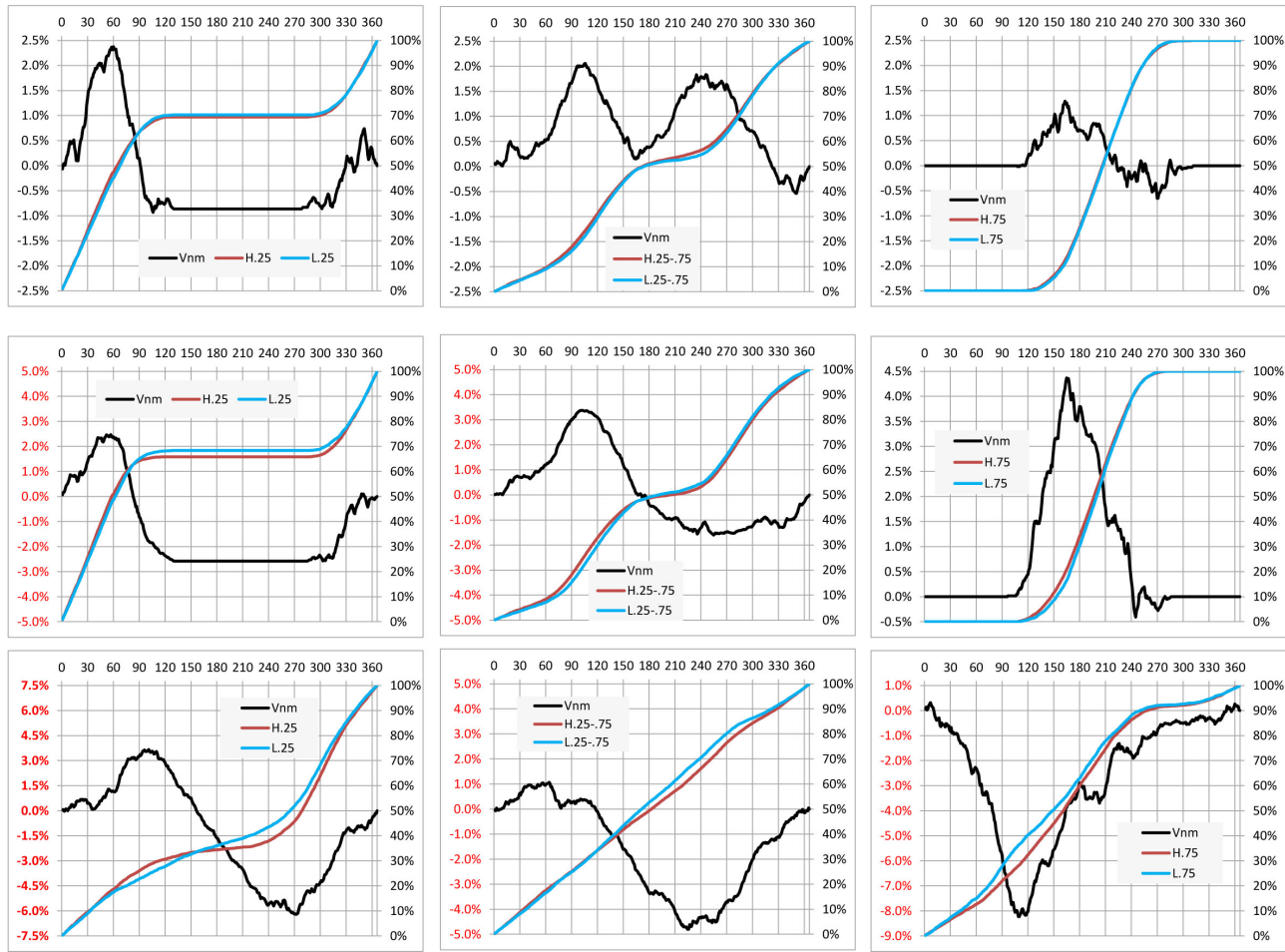

Figure 10. Empirical probability distribution functions (primary axis on the right) $F_{H}(\Delta)$ (red) and $F_{L}(\Delta)$ (blue) for the low, middle, and high range values of daily minimum temperature TN (top row), daily maximum temperature TX (middle row), and daily temperature range $\Delta \mathrm{T}$ (bottom row) in the periods of high and low solar activity at the ten European stations. The differences $D(\Delta)=F_{H}(\Delta)-\mathrm{F}_{L}(\Delta)$ are plotted in black (secondary axis on the left). 
Table 4. The Kuiper test statistic $\kappa$ and probability $\alpha$ for the TN, TX, and $\Delta \mathrm{T}$ temperature indices in the solar cycles of high versus low activity. The three rows for each of the ten stations correspond to the low (1st quartile), middle $\left(2^{\text {nd }}\right.$ and $3^{\text {rd }}$ quartiles $)$, and upper $\left(4^{\text {th }}\right.$ quartile) ranges of a temperature index. The statistical significance levels $\alpha<5 \%$ given in red approve with confidence above $95 \%$ different distributions of the preferred days of a year for the normal and extremal values.

\begin{tabular}{|c|c|c|c|c|c|c|c|}
\hline \multirow{2}{*}{ Station } & \multirow{2}{*}{ Range } & \multicolumn{2}{|c|}{ TN } & \multicolumn{2}{|c|}{ TX } & \multicolumn{2}{|c|}{$\Delta \mathrm{T}$} \\
\hline & & $\kappa$ & $a$ & $\kappa$ & $a$ & $\kappa$ & $a$ \\
\hline \multirow{3}{*}{$\begin{array}{c}\text { Oxford } \\
\text { (United Kingdom) }\end{array}$} & low & 2.552 & 0.0001 & 1.760 & 0.0465 & 1.890 & 0.0210 \\
\hline & middle & 3.723 & $<0.0001$ & 3.427 & $<0.0001$ & 1.506 & $<0.0001$ \\
\hline & high & 2.533 & 0.0001 & 1.773 & 0.0430 & 1.983 & 0.0113 \\
\hline \multirow{3}{*}{ Uccle (Belgium) } & low & 2.121 & 0.0042 & 0.957 & 0.8705 & 4.609 & $<0.0001$ \\
\hline & middle & 3.614 & $<0.0001$ & 1.314 & 0.3735 & 2.024 & $<0.0001$ \\
\hline & high & 1.471 & 0.2018 & 1.650 & 0.0855 & 1.444 & 0.2263 \\
\hline \multirow{3}{*}{ Frankfurt (Germany) } & low & 3.818 & $<0.0001$ & 3.962 & $<0.0001$ & 1.481 & 0.1931 \\
\hline & middle & 2.615 & 0.0001 & 3.020 & $<0.0001$ & 1.518 & 0.1636 \\
\hline & high & 1.558 & 0.1355 & 2.054 & 0.0069 & 3.200 & $<0.0001$ \\
\hline \multirow{3}{*}{ Wien (Austria) } & low & 1.858 & 0.0257 & 1.481 & 0.1937 & 3.014 & $<0.0001$ \\
\hline & middle & 3.746 & $<0.0001$ & 4.791 & $<0.0001$ & 2.397 & 0.0004 \\
\hline & high & 2.113 & 0.0045 & 1.792 & 0.0385 & 1.817 & 0.0331 \\
\hline \multirow{3}{*}{$\begin{array}{c}\text { Prague } \\
\text { (Czech Republic) }\end{array}$} & low & 0.951 & 0.8772 & 0.724 & 0.9947 & 2.427 & 0.0003 \\
\hline & middle & 2.301 & 0.0010 & 4.172 & $<0.0001$ & 2.899 & $<0.0001$ \\
\hline & high & 1.237 & 0.4807 & 1.676 & 0.0743 & 1.960 & 0.0132 \\
\hline \multirow{3}{*}{ Milan (Italy) } & low & 3.523 & $<0.0001$ & 1.054 & 0.7513 & 2.836 & $<0.0001$ \\
\hline & middle & 8.346 & $<0.0001$ & 3.378 & $<0.0001$ & 9.173 & $<0.0001$ \\
\hline & high & 4.320 & $<0.0001$ & 1.907 & 0.0188 & 2.822 & $<0.0001$ \\
\hline \multirow{3}{*}{ Bologna (Italy) } & low & 1.698 & 0.0659 & 1.187 & 0.5547 & 1.829 & 0.0308 \\
\hline & middle & 1.369 & 0.3067 & 4.441 & $<0.0001$ & 8.480 & $<0.0001$ \\
\hline & high & 1.344 & 0.3360 & 4.502 & $<0.0001$ & 5.071 & $<0.0001$ \\
\hline \multirow{3}{*}{$\begin{array}{c}\text { St Petersburg } \\
\text { (Russian Federation) }\end{array}$} & low & 2.532 & 0.0001 & 5.470 & $<0.0001$ & 2.164 & 0.0030 \\
\hline & middle & 4.962 & $<0.0001$ & 5.021 & $<0.0001$ & 1.037 & 0.7745 \\
\hline & high & 3.954 & $<0.0001$ & 2.213 & 0.0021 & 4.516 & $<0.0001$ \\
\hline \multirow{3}{*}{$\begin{array}{c}\text { Astrakhan } \\
\text { (Russian Federation) }\end{array}$} & low & 1.398 & 0.2736 & 1.618 & 0.1007 & 4.620 & $<0.0001$ \\
\hline & middle & 2.952 & $<0.0001$ & 5.253 & $<0.0001$ & 4.227 & $<0.0001$ \\
\hline & high & 2.029 & 0.0082 & 1.479 & 0.1948 & 4.488 & $<0.0001$ \\
\hline \multirow{3}{*}{$\begin{array}{c}\text { Arkhangelsk } \\
\text { (Russian Federation) }\end{array}$} & low & 1.773 & 0.0430 & 2.459 & 0.0003 & 4.851 & $<0.0001$ \\
\hline & middle & 1.976 & 0.0119 & 3.415 & $<0.0001$ & 4.052 & $<0.0001$ \\
\hline & high & 1.482 & 0.1922 & 2.270 & 0.0013 & 3.906 & $<0.0001$ \\
\hline
\end{tabular}


Table 5. The Kuiper test statistics $V$, $\kappa$, and probability $\alpha$ for the PP index in the solar cycles of high versus low activity. Note: The statistical significance levels $\alpha<5 \%$ given in red confirm, with confidence above $95 \%$, different distributions of the preferred times of a year for the low and high values of the ECA \& D daily sea level pressure index PP.

\begin{tabular}{|c|c|c|c|c|c|c|c|c|c|}
\hline \multirow{2}{*}{ Station and Location } & \multicolumn{3}{|c|}{$\begin{array}{c}\text { Low } \\
\left(1^{\text {st }} \text { quartile }\right)\end{array}$} & \multicolumn{3}{|c|}{$\begin{array}{c}\text { Middle } \\
\left(2^{\text {nd }} \text { and } 3^{\text {rd }} \text { quartiles }\right)\end{array}$} & \multicolumn{3}{|c|}{$\begin{array}{c}\text { High } \\
\left(4^{\text {th }} \text { quartile }\right)\end{array}$} \\
\hline & $V$ & $\kappa$ & $a$ & $V$ & $\kappa$ & $a$ & $V$ & $\kappa$ & $a$ \\
\hline De Bilt (NL) & & & & & & & & & \\
\hline $\begin{array}{c}52^{\circ} 05^{\prime} 56^{\prime \prime} \mathrm{N} \\
5^{\circ} 10^{\prime} 46^{\prime \prime} \mathrm{E}\end{array}$ & 0.0368 & 2.222 & 0.0019 & 0.0126 & 1.079 & 0.7164 & 0.0507 & 3.063 & $<0.0001$ \\
\hline Armagh (UK) & & & & & & & & & \\
\hline $\begin{array}{l}54^{\circ} 21^{\prime} 00^{\prime \prime} \mathrm{N} \\
6^{\circ} 39^{\prime} 00^{\prime \prime} \mathrm{W}\end{array}$ & 0.0277 & 1.632 & 0.0939 & 0.0097 & 0.941 & 0.8875 & 0.1147 & 3.314 & $<0.0001$ \\
\hline
\end{tabular}

Paris-Montsouris (FR)

$\begin{array}{llllllllll}48^{\circ} 49^{\prime} 18^{\prime \prime} \mathrm{N}, & 0.0359 & 1.809 & 0.0347 & 0.0133 & 1.024 & 0.7914 & 0.0383 & 1.993 & 0.0105\end{array}$ $2^{\circ} 20^{\prime} 16^{\prime \prime} \mathrm{E}$
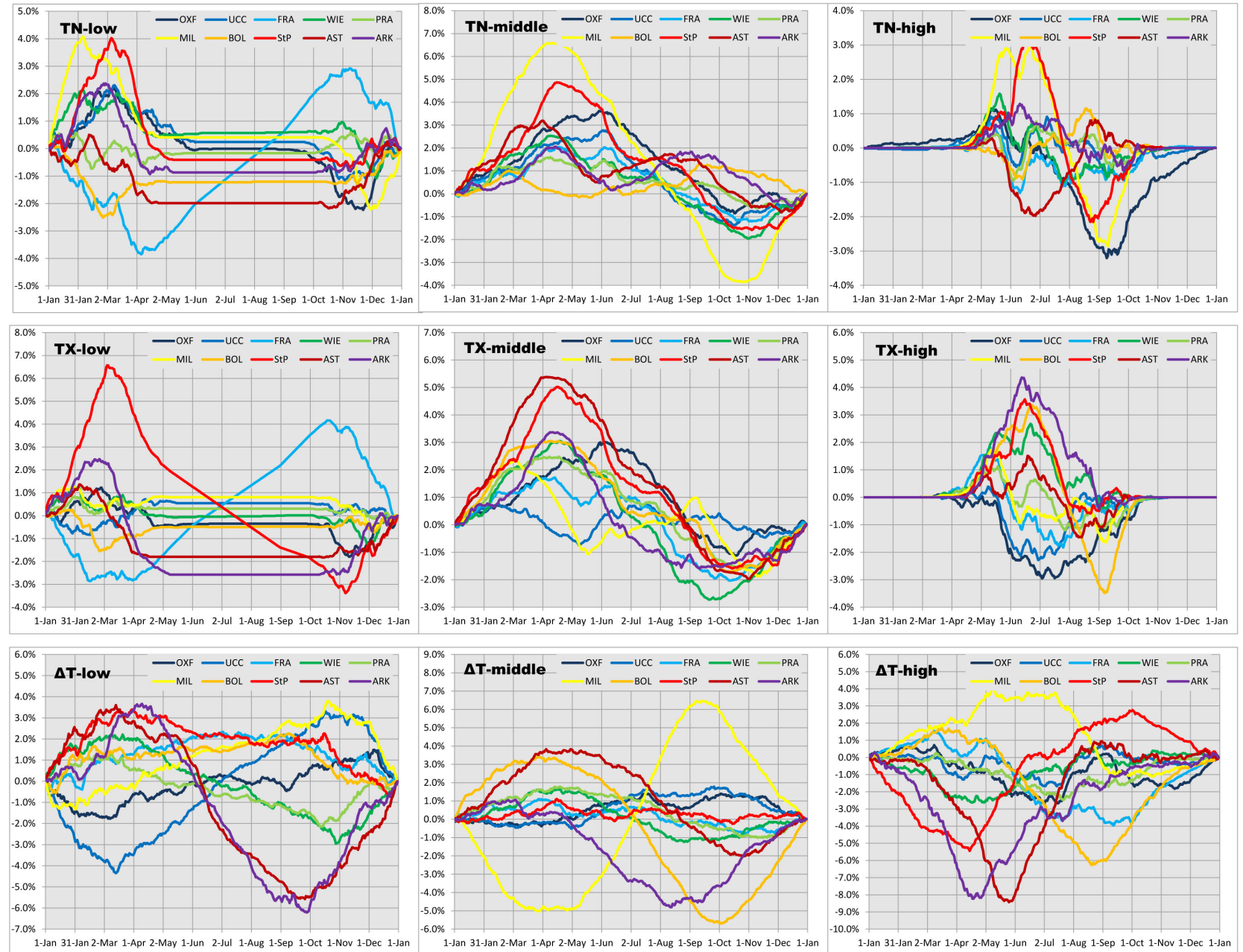

Figure 11. The differences $D(\tau)=F_{H}(\tau)-F_{L}(\tau)$ for the Julian daily rate of the low, middle, and high values of minimum temperature TN (top row), daily maximum temperature TX (middle row), and daily temperature range $\Delta \mathrm{T}$ (bottom row) in the periods of high and low solar activity at the ten European meteorological stations. 

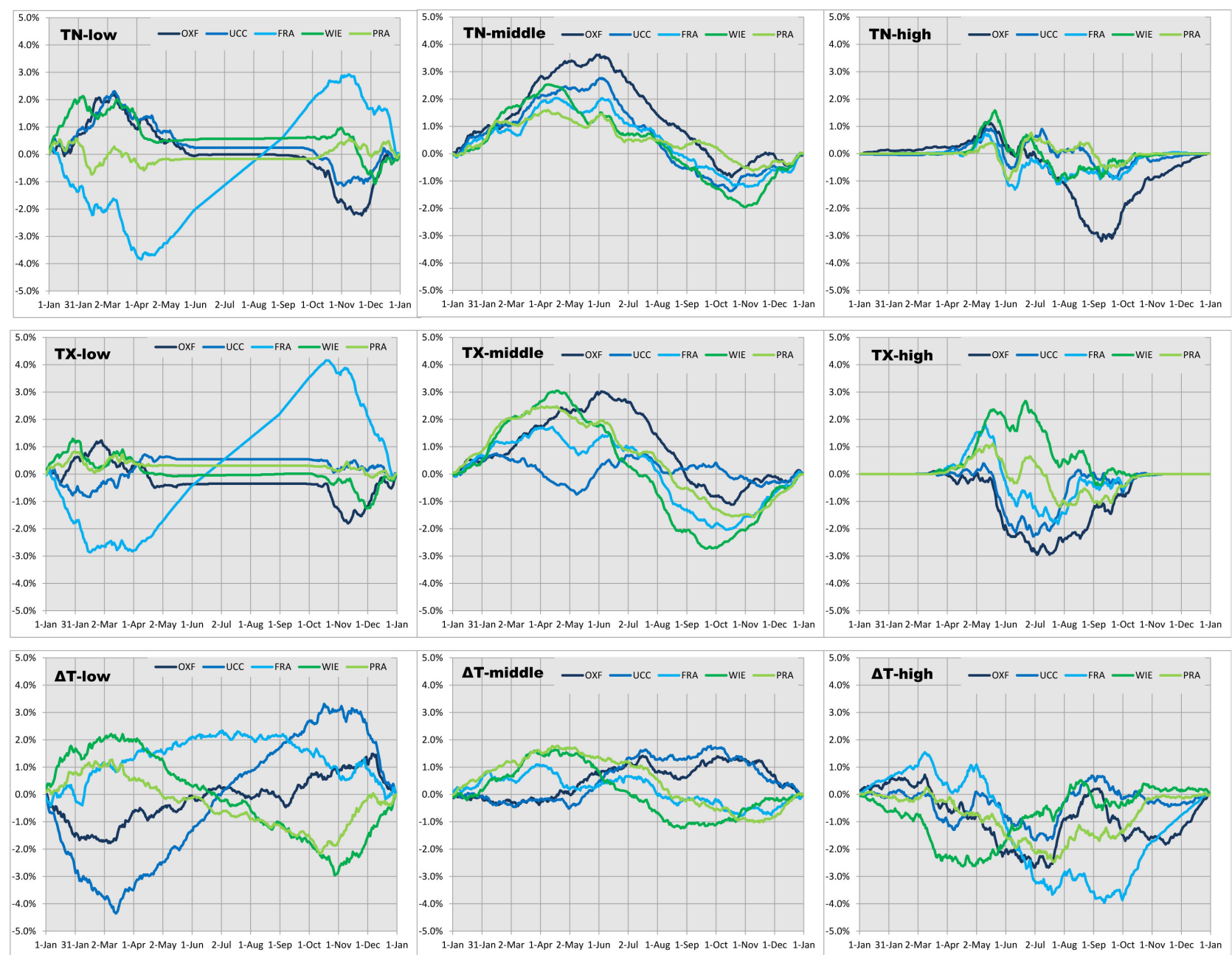

Figure 12. The differences $D(\tau)=F_{H}(\tau)-F_{L}(\tau)$ for the Julian daily rate of extremes and normal values of minimum temperature $\mathrm{TN}$ (top row), daily maximum temperature TX (middle row), and daily temperature range $\Delta \mathrm{T}$ (bottom row) in the periods of high and low solar activity at the five European meteorological stations of the same Köppen-Geiger climate class Cfb.

Figure 8, Table 2 and Table 3). Specifically, when the data are split into the $H$ and $L$ subsets of temperatures in solar cycles of high and low activity, the average daily differences $T_{H}-T_{L}$ present many stable features including periods of large-amplitude variations lasting for 1.5 to 3 months. The amplitude of the average daily differences reaches $2^{\circ} \mathrm{C}$ which is on the order of or even larger than the amplitude of multi-decadal to secular variations observed on global mean temperature curves over the past 150 years. Moreover, statistical significance of the partition of temperatures based on solar activity that had been proved by the results of random shuffling of cycles for the longest temperature series from three observatories [2] has been confirmed for the data from seven other meteorological stations in different Köppen-Geiger climate zones of Europe.

The $T_{H}-T_{L}$ patterns carry a regional signature (at the scale of Western Europe), modulated by a more local response function. For instance, the five observatories in a zone extending from Oxford in the West to Prague in the East have very similar signatures as shown in Figure 7. On the other hand, the 


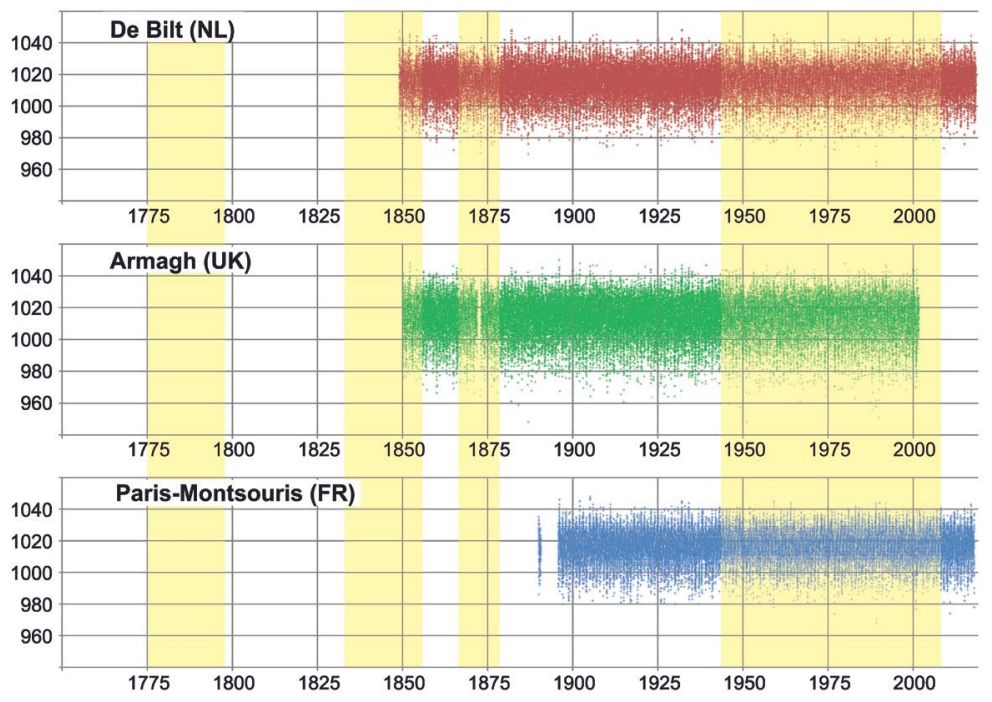

Figure 13. The ECA \& D of the daily sea level pressure PP [11].
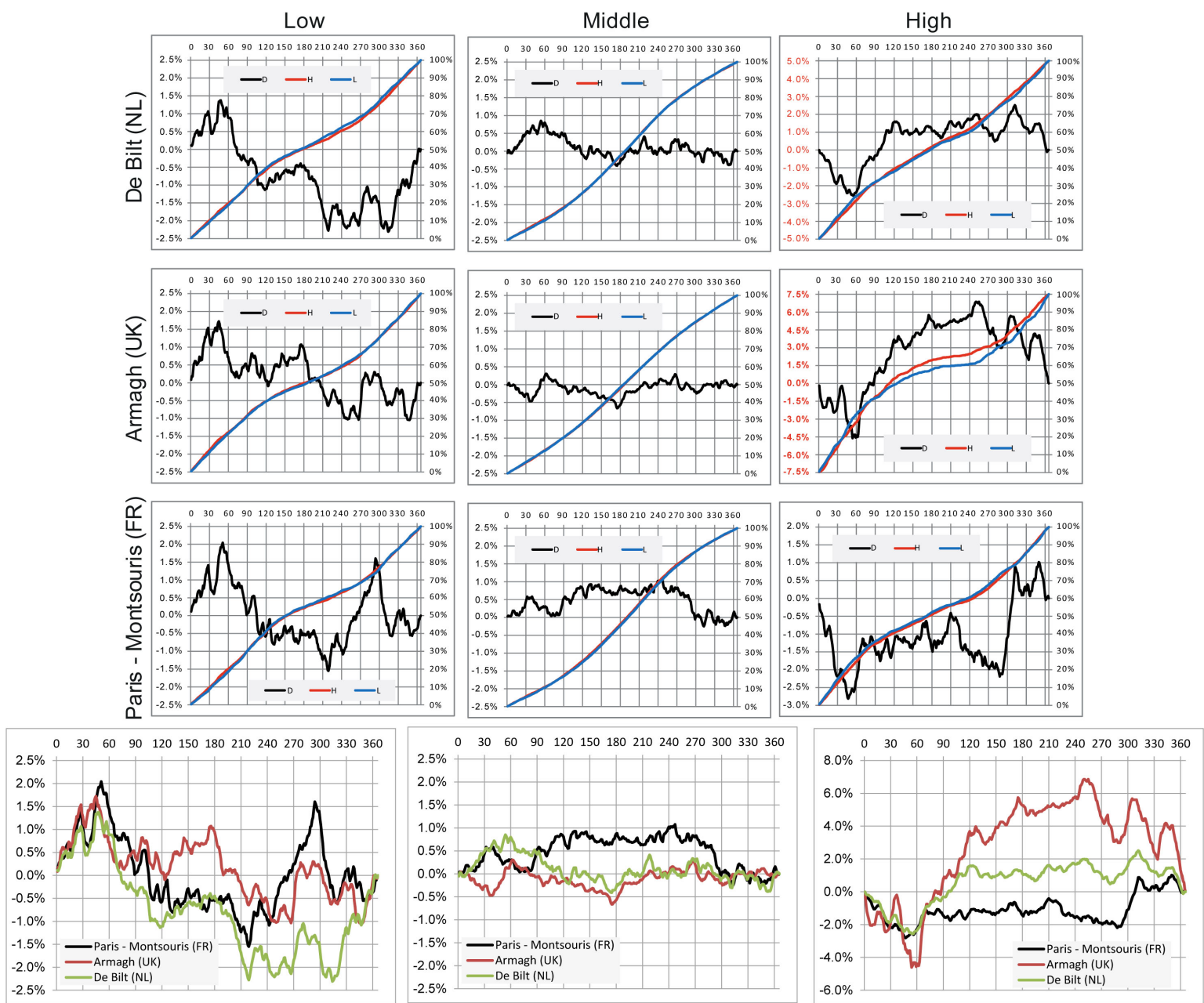

Figure 14. Empirical probability distribution functions (primary axis on the right) $F_{H}(\Delta)$ (red) and $F_{L}(\Delta)$ (blue) for the daily rate of low, middle, and high range values of the sea level pressure and their the differences $D(\Delta)=F_{H}(\Delta)-F_{L}(\Delta)$ (black, secondary axis on the left) at the three meteorological observatories. Bottom row displays the $D(\Delta)$ graphs for the three observatories together. 
observatories of Milan, Bologna, St Petersburg, Arkhangelsk and Astrakhan, representing five different Köppen-Geiger climate classes, have different signatures and correspond to different regional responses of climate to solar forcing. We note however that the curves for Milan bear some resemblance to the "Oxford to Prague" group, whereas those for Bologna do not (although Milan does not belong to the climate class of the group, whereas Bologna does). This emphasizes the importance of local to regional details (including topography) in determining the response of temperatures to solar forcing at a given station. If we average the results for all ten observatories (Figure 8, bottom), the amplitude of resulting "common" features is much diminished: regional effects are partly smoothed out due to averaging of the different complex regional responses of atmospheric circulation to solar irradiance (at all wavelengths). This is an expected consequence of the multi-scale behaviour of terrestrial climate.

Finally, a pilot application of the Kuiper test to the sea level pressure index of three of the ECA \& D longest series of stations De Bilt, Armagh, and Paris-Montsouris discloses similar solar forcing effect related, presumably, to solar activity at scale of a few 11-year cycles.

We have extended and confirmed the conclusions of our previous papers [1] [2]: we have introduced seven more stations with long records, coming now to a total of ten European stations from five distinct Köppen climatic classes, and we have complemented the Kolmogorov-Smirnov statistical test with the powerful Kuiper test. The significant redistribution of ranges of temperature indices is confirmed on the solid statistical basis of the Kuiper test results for all ten observatories considered (Table 4). However, the responses to solar forcing in high versus low activity cycles may display some differences, even for the sites in the same climatic zone (Figure 12). This additional work confirms beyond reasonable doubt that annual changes in temperature minima, maxima and ranges are sensitive to the level of solar activity. The confidence levels on the various nonparametric statistical tests are in most stations and for most series better than $99 \%$ and often much better.

It is difficult to believe that the variations depicted for the ECA \& D temperature and pressure indices in Figure 8, Figure 11, and Figure 14 (bottom) could be due to spurious effects. The similarities between individual curves displayed in the bottom lines of Figure 7 and Figure 14 are highly unlikely to be due to pure chance: presumably, they are linked to solar activity. This is supported by many independent lines of evidence. For instance, Le Mouël et al. [18] have applied singular spectrum analysis (SSA) to the international sunspot number (ISSN; 1849-2015) and the count of polar faculae (PF; 1906-2006). Perhaps not surprisingly, the SSA method finds 22, 11 and 5.5-year components as the first eigenvectors of these solar activity proxies. Le Mouël et al. (2019) next applied SSA to some of the major climate indices: MJO, PDO, ENSO, WPO, AAO and AMO among others. They find that the first SSA eigenvectors are all combinations of 11, 5.5 and 3.6-year pseudo-cycles. All these periods have long been attributed to solar activity, and this by itself argues for the existence of a strong 
link between solar activity and climate. The mechanisms of coupling must be complex and probably non-linear but they remain to be fully understood (UV radiation, solar wind and galactic cosmic rays being the most promising candidates).

In addition, these results show that, in ECA \& D, errors due to instrumental problems or linked to observers are very unlikely to have had a significant part in these signals. On the contrary, they confirm the quality of these long series of observations taken at their face value.

A consequence of our studies is that parameters linking solar activity to regional climate response, such as climate sensitivity, may need to be revisited [19] [20]. As a matter of fact, the evidence of a significant influence of solar activity on climate is not fully captured in model predictions [21] [22] [23]. Apparently, the long-term variability of solar forcing cannot be ignored (e.g., [24] [25] [26] [27]). There is ongoing debate over the fidelity and utility of global climate models which are missing the norm for practical applications, i.e., formal model verification and validation [28] [29]. Many authors have argued that the period of high solar activity in the second half of the 20th century is unique (e.g., [30] [31]). Evidently, the past and present behavior of the Sun [25] [32] suggests that it may be undergoing a transition to a lower energy state. Some authors even envisage a possible scenario of solar cooling, analogous to the solar minimum that may lead to a new ice age [33]. A comprehensive picture of the solar effect on temperature of the lower atmosphere in the long term is still out of reach, given the complexities, multi-scale character and nonlinear behavior of the processes and responses involved. We have attempted to contribute to a better understanding of the climate system, through robust statistical testing of null hypotheses against the existing long series of the original observations. Although there is a diversity of long-term temperature responses to varying levels of solar activity in European observatories with the longest records, the signature of variations of this solar activity is unmistakable in these long-term responses.

\section{Conflicts of Interest}

The authors declare no conflicts of interest regarding the publication of this paper.

\section{References}

[1] Le Mouël, J.-L., Kossobokov, V. and Courtillot, V. (2010) A Solar Pattern in the Longest Temperature Series from Three Stations in Europe. Journal of Atmospheric and Solar-Terrestrial Physics, 72, 62-76.

[2] Kossobokov, V., Le Mouël, J.-L. and Courtillot, V. (2010) A Statistically Significant Signature of Multi-Decadal Solar Activity Changes in Atmospheric Temperatures at Three European Stations. Journal of Atmospheric and Solar-Terrestrial Physics, 72 , 595-606.

[3] Legras, B., Mestre, O., Bard, E. and Yiou, P. (2010) On Misleading Solar-Climate Relationship. Climate of the Past Discussions, 6, 767-800. 
[4] Kossobokov, V., Le Mouël, J.-L. and Courtillot, V. (2010) Response to Comment: "On Misleading Solar-Climate Relationship" by B. Legras, et al. Climate of the Past Discussions, 6, C342. http://www.clim-past-discuss.net/6/C342/2010/cpd-6-C342-2010-supplement.pdf

[5] Le Mouël, J.-L., Blanter, E., Courtillot, V., Kossobokov, V. and Shnirman, M. (2011) A Note on Comments on Papers Published in Journal of Atmospheric and Solar-Terrestrial Physics and Our Responses. Journal of Atmospheric and Solar-Terrestrial Physics, 73, 2042. https://doi.org/10.1016/j.jastp.2011.04.001

[6] Wolff, E., Barbante, C., Goosse, H., Kiefer, T. and Rousseau, D.-D. (2011) Clarifications about the Concept and Review Process of Climate of the Past. Journal of Atmospheric and Solar-Terrestrial Physics, 73, 2043. https://doi.org/10.1016/j.jastp.2011.06.013

[7] Yiou, P., Bard, E., Dandin, P., Legras, B., Naveau, P., Rust, H.W., Terray, L. and Vrac, M. (2010) Statistical Issues about Solar-Climate Relations. Climate of the Past, 6, 565-573. https://doi.org/10.5194/cp-6-565-2010

[8] Kossobokov, V., Le Mouël, J.-L. and Allègre, C. (2012) Spatial and Temporal Variations of Climate in Europe. Atmospheric and Climate Sciences, 2, 568-581. https://doi.org/10.4236/acs.2012.24052

[9] Kottek, M., Grieser, J., Beck, C., Rudolf, B. and Rubel, F. (2006) World Map of the Köppen-Geiger Climate Classification Updated. Meteorologische Zeitschrift, 15, 259-263. https://doi.org/10.1127/0941-2948/2006/0130

[10] Press, W.H., Teukolsky, S.A., Vetterling, W.T. and Flannery, B.P. (1992) Numerical Recipes in C: The Art of Scientific Computing. 2nd Edition, Cambridge University Press, New York, 994 p.

[11] Klein Tank, A.M.G., et al. (2002) Daily Dataset of 20th-Century Surface Air Temperature and Precipitation Series for the European Climate Assessment. International Journal of Climatology, 22, 1441-1453. https://doi.org/10.1002/joc.773

[12] Parker, D.E., Legg, T.P. and Folland, C.K. (1992) A New Daily Central England Temperature Series, 1772-1991. International Journal of Climatology, 12, 317-342. https://doi.org/10.1002/joc.3370120402

[13] SIDC-Team (2018) World Data Center for the Sunspot Index, Royal Observatory of Belgium, Monthly Report on the International Sunspot Number, Online Catalogue of the Sunspot Index. http://www.sidc.be/silso/datafiles

[14] Kolmogorov, A. (1933) Sulla determinazione empirica di una legge di distribuzione. Giornale dell Istituto Italiano degli Attuari, 4, 83-91.

[15] Smirnov, N. (1948) Table for Estimating the Goodness of Fit of Empirical Distributions. Annals of Mathematical Statistics, 19, 279-281. https://doi.org/10.1214/aoms/1177730256

[16] Kuiper, N.H. (1960) Tests Concerning Random Points on a Circle. Proceedings of the Koninklijke Nederlandse Akademie van Wetenschappen, Series A, 63, 38-47.

[17] Stephens, M.A. (1965) The Goodness-of-Fit Statistic VN: Distribution and Significance Points. Biometrica, 52, 309-321. https://doi.org/10.1093/biomet/52.3-4.309

[18] Le Mouël, J.-L., Lopes, F. and Courtillot, V. (2019) A Solar Signature in Many Climate Indices. Journal of Geophysical Research: Atmospheres, 124, 2600-2619. https://doi.org/10.1029/2018JD028939

[19] Chylek, P., Lihmann, U., Dubey, M., Mishchenko, M., Kahn, R. and Ohmura, A. (2007) Limits on Climate Sensitivity Derived from Recent Satellite and Surface Ob- 
servations. Journal of Geophysical Research: Atmospheres, 112, D24S04. https://doi.org/10.1029/2007JD008740

[20] Easterling, D.R. and Wehner, M.F. (2009) Is the Climate Warming or Cooling? Geophysical Research Letters, 36, L08706. https://doi.org/10.1029/2009GL037810

[21] De Jager, C. (2005) Solar Forcing of Climate. 1: Solar Variability. Space Science Reviews, 120, 197-241. https://doi.org/10.1007/s11214-005-7046-5

[22] Scafetta, N. and West, B.J. (2007) Phenomenological Reconstructions of the Solar Signature in the Northern Hemisphere Surface Temperature Records Since 1600. Journal of Geophysical Research: Atmospheres, 112, D24S03. https://doi.org/10.1029/2007JD008437

[23] Camp, C.D. and Tung, K.K. (2007) Surface Warming by the Solar Cycle as Revealed by the Composite Mean Difference Projection. Geophysical Research Letters, 34, L14703. https://doi.org/10.1029/2007GL030207

[24] Usoskin, I.G., Schussler, M., Solanki, S.K. and Mursula, K. (2005) Solar Activity, Cosmic Rays, and Earth's Temperature: A Millennium-Scale Comparison. Journal of Geophysical Research: Space Physics, 110, A10102. https://doi.org/10.1029/2004JA010946

[25] De Jager, C. (2008) Solar Activity and Its Influence on Climate. Netherlands Journal of Geosciences, 87, 207-213. https://doi.org/10.1017/S0016774600023283

[26] Scafetta, N. and West, B.J. (2008) Is Climate Sensitive to Solar Variability? Physics Today, 61, 50-51. https://doi.org/10.1063/1.2897951

[27] Soon, W., Connolly, R. and Connolly, M. (2015) Re-Evaluating the Role of Solar Variability on Northern Hemisphere Temperature Trends Since the 19th Century. Earth-Science Reviews, 150, 409-452. https://doi.org/10.1016/j.earscirev.2015.08.010

[28] Stevens, B. and Bony, S. (2013) What Are Climate Models Missing? Science, 340, 1053-1054. https://doi.org/10.1126/science.1237554

[29] Curry, J. (2017) Climate Models for the Layman. The Global Warming Policy Foundation, $20 \mathrm{p}$.

[30] Usoskin, I.G., Solanki, S.K., Schussler, M., Mursula, K. and Alanko, K. (2003) Millennium Scale Sunspot Number Reconstruction: Evidence for an Unusually Active Sun Since the 1940's. Physical Review Letters, 91, 211101. https://doi.org/10.1103/PhysRevLett.91.211101

[31] Soon W.W.-H., Connolly, R., Connolly, M., O’Neill, P., Zheng, J., Ge, J.Q., Hao, Z. and Yan, H. (2018) Comparing the Current and Early 20th Century Warm Periods in China. Earth-Science Reviews, 185, 80-101. https://doi.org/10.1016/j.earscirev.2018.05.013

[32] Kossobokov, V.G., Le Mouël, J.-L. and Courtillot, V. (2016) Solar Flares on Transition from the Grand Maximum to the Minimum? In: Jones, S.L., Ed., Solar Flares. Investigations and Selected Research, Nova Science Publishers, Hauppauge, New York, 81-100.

[33] Abdussamatov, H. (2015) Current Long-Term Negative Average Annual Energy Balance of the Earth Leads to the New Little Ice Age. Thermal Science, 19, S279-S288. 